OPEN ACCESS

Edited by:

Karsten Kretschmer,

Technische Universität Dresden,

Germany

Reviewed by:

Paolo Monti,

San Raffaele Hospital (IRCCS), Italy

Abdelhadi Saoudi,

Institut National de la Santé et

de la Recherche Médicale

(INSERM), France

*Correspondence:

Alexander Scheffold

alexander.scheffold@charite.de

Specialty section:

This article was submitted to Immunological Tolerance and Regulation,

a section of the journal

Frontiers in Immunology

Received: 05 December 2017

Accepted: 23 January 2018

Published: 07 February 2018

Citation:

Nowak A, Lock D, Bacher P, Hohnstein T, Vogt K, Gottfreund J, Giehr P, Polansky JK, Sawitzki B, Kaiser A, Walter $J$ and Scheffold A (2018) CD137+CD154- Expression As a Regulatory T Cell (Treg)-Specific Activation Signature for Identification and Sorting of Stable Human Tregs from In Vitro Expansion Cultures.

Front. Immunol. 9:199. doi: 10.3389/fimmu.2018.00199

\section{CD137+CD154- Expression As a Regulatory T Cell (Treg)-Specific Activation Signature for Identification and Sorting of Stable Human Tregs from In Vitro Expansion Cultures}

\author{
Anna Nowak ${ }^{1}$, Dominik Lock ${ }^{2}$, Petra Bacher ${ }^{3}$, Thordis Hohnstein ${ }^{3}$, Katrin Vogt ${ }^{4}$, \\ Judith Gottfreund ${ }^{5}$, Pascal Giehr ${ }^{5}$, Julia K. Polansky ${ }^{6}$, Birgit Sawitzki ${ }^{4}$, Andrew Kaiser ${ }^{2}$, \\ Jörn Walter ${ }^{5}$ and Alexander Scheffold ${ }^{1,3 *}$ \\ ${ }^{1}$ German Rheumatism Research Centre (DRFZ) Berlin, Leibniz Association, Berlin, Germany, ${ }^{2}$ Miltenyi Biotec GmbH, \\ Bergisch Gladbach, Germany, ${ }^{3}$ Department of Cellular Immunology, Clinic for Rheumatology and Clinical Immunology, \\ Charité - University Medicine, Berlin, Germany, ${ }^{4}$ Institute for Medical Immunology, Charité - University Medicine, Berlin, \\ Germany, ${ }^{5}$ Department of Genetics/Epigenetics, Saarland University, Saarbrücken, Germany, ${ }^{6}$ Berlin-Brandenburg Center \\ for Regenerative Therapies (BCRT), Charité - University Medicine, Berlin, Germany
}

Regulatory T cells (Tregs) are an attractive therapeutic tool for several different immune pathologies. Therapeutic Treg application often requires prolonged in vitro culture to generate sufficient Treg numbers or to optimize their functionality, e.g., via genetic engineering of their antigen receptors. However, purity of clinical Treg expansion cultures is highly variable, and currently, it is impossible to identify and separate stable Tregs from contaminating effector T cells, either ex vivo or after prior expansion. This represents a major obstacle for quality assurance of expanded Tregs and raises significant safety concerns. Here, we describe a Treg activation signature that allows identification and sorting of epigenetically imprinted Tregs even after prolonged in vitro culture. We show that short-term reactivation resulted in expression of CD137 but not CD154 on stable FoxP3+ Tregs that displayed a demethylated Treg-specific demethylated region, high suppressive potential, and lack of inflammatory cytokine expression. We also applied this Treg activation signature for rapid testing of chimeric antigen receptor functionality in human Tregs and identified major differences in the signaling requirements regarding CD137 versus CD28 costimulation. Taken together, CD137+CD154- expression emerges as a universal Treg activation signature ex vivo and upon in vitro expansion allowing the identification and isolation of epigenetically stable antigen-activated Tregs and providing a means for their rapid functional testing in vitro.

Keywords: regulatory $\mathbf{T}$ cells, chimeric antigen receptor, adoptive regulatory $\mathbf{T}$ cell therapy, regulatory $\mathrm{T}$ cell stability, regulatory $\mathrm{T}$ cell expansion, regulatory $\mathrm{T}$ cell signaling, $\mathrm{CD} 137$

Abbreviations: Treg, regulatory T cell; Teff, effector T cell; CAR, chimeric antigen receptor; TCR, T cell receptor; scFv, singlechain variable fragment; Dex, dextran; GvHD, graft-versus-host disease; T1D, type 1 diabetes; EAE, experimental autoimmune encephalomyelitis; TSDR, Treg-specific demethylated region. 


\section{INTRODUCTION}

Adoptive transfer of regulatory T cells (Tregs) represents an attractive approach to exploit physiological self-regulating capacities for prevention or treatment of immune-mediated pathologies such as graft-versus-host disease (GvHD), organ transplantation, or chronic inflammatory diseases. Transfer of polyclonal Tregs, either ex vivo $(1,2)$ or after in vitro expansion, has been shown to be safe and effective for prevention of GvHD (3-8). In autoimmune diseases Treg treatment also seems to be safe, but therapeutic efficiency has so far not been sufficiently demonstrated (9-13). Essentially, within polyclonal Treg populations, the number of Tregs with therapeutically relevant specificity may be too small to achieve optimal clinical effects. This might be overcome by increased Treg doses or alternatively via selection of Tregs with disease-relevant specificities. Indeed, experimental models have demonstrated increased therapeutic potential of antigen-specific Tregs compared to polyclonal Tregs, e.g., by targeting disease-relevant autologous or allogeneic antigens in type 1 diabetes (T1D) (14-17), GvHD (18-25), experimental autoimmune encephalomyelitis (EAE) $(26,27)$, and arthritis $(28,29)$. However, generation of antigen-specific Tregs and thus their therapeutic application is currently limited by their low frequencies, limited knowledge about the identity of diseaserelevant target antigens, and lack of technologies for antigenspecific Treg selection and expansion. Therefore, genetic engineering has been used to redirect antigen-specificity of human Tregs using transgenic $\mathrm{T}$ cell receptors (TCRs) (30-32) or chimeric antigen receptors (CARs). The immunosuppressive potential of CAR-Tregs, which can be universally applied to all donors independent of matched MHC alleles, has been shown to prevent development of EAE (33), colitis (34-36), GvHD (37-39), allergic airway inflammation (40), and neutralizing immune responses against Factor VIII (41) in mice. Most importantly, improved Treg-based therapies largely depend on efficient technologies for the in vitro expansion and manipulation of their functional properties. However, in vitro cultured Tregs display highly variable purities resulting from contaminating effector $\mathrm{T}$ cells (Teffs) or potential Treg instability. So far, there are no markers for the rapid identification and sorting of stable Tregs from such expansion cultures. To date, FoxP3 expression and above all demethylation of a Treg-specific demethylated region (TSDR) within the FoxP3 locus represent the gold standard for estimating the fraction of stable Tregs within a population (42-45), yet both do not allow for sorting of the specific subset.

In particular for Tregs equipped with disease-relevant antigen receptors, e.g., autoantigens, the risk to generate unpredictable numbers of Teffs with disease-amplifying potential has to be tightly controlled. However, the lack of discriminative markers also affects systematic functional optimization of in vitro generated Tregs, e.g., by genetic engineering. For example, transgenic TCR or CAR constructs may need to fulfill different requirements in Tregs versus Teffs, which is currently difficult to test in mixed cultures without clear-cut discriminative markers. Thus, the lack of markers for the identification of stable Tregs represents a major obstacle for the generation of expanded and functionally optimized Tregs for clinical applications.
A number of Treg-specific, activation-induced surface markers, such as CD137 (46-48), CD121a/b, LAP, GARP (49-51) or Ox40/ CD39 (52), have been described to identify activated Tregs ex vivo. Among those, CD137 is expressed after only 5-7 h of antigenic stimulation and has been proven to be highly specific for Tregs $(46,47)$, allowing their ex vivo discrimination from CD137-CD154+ Teffs. CD137 expression enabled the specific enrichment of antigen-activated Tregs ex vivo, displaying all features of thymic Tregs such as a demethylated TSDR and a Treg-specific expression profile, including high levels of FoxP3, Helios, CTLA4, and lack of CD127 and effector cytokines $(46,47)$. After polyclonal stimulation of Tregs ex vivo, Schoenbrunn et al. further demonstrated that co-staining of CD137 and CD154 allowed further enrichment of stable Tregs by exclusion of $\mathrm{T}$ cells co-expressing both markers (48). Whether this Treg signature is also maintained after activation and expansion in vitro and still allows discrimination from instable Tregs or Teffs are not known but would strongly improve current possibilities for optimal in vitro expansion of Tregs. Here, we show that after brief polyclonal or antigen-specific stimulation, CD137+CD154- expression represents a universal Treg-specific activation signature for the identification and sorting of stable, TSDR demethylated Tregs after prior in vitro expansion.

\section{MATERIALS AND METHODS}

\section{Treg Isolation}

Leukapheresis products from healthy donors were obtained from the Charité University Hospital, Berlin, Germany, with informed consent according to ethical guidelines. PBMCs were obtained by Ficoll-Paque (GE Healthcare Life Sciences, Freiburg, Germany) gradient centrifugation. CD25+ Tregs were isolated from PBMCs according to manufacturer's recommendations using CD25 microbeads (Miltenyi Biotec, Bergisch Gladbach, Germany). Tregs were cultured in "Treg expansion medium" consisting of TexMACS medium (Miltenyi Biotec, Bergisch Gladbach, Germany) $+5 \%(\mathrm{v} / \mathrm{v})$ human AB-serum (Sigma-Aldrich, Schnelldorf, Germany) + 100 U/ml IL-2 + 100 nmol rapamycin (both Miltenyi Biotec, Bergisch Gladbach, Germany) and $100 \mathrm{U} / \mathrm{ml}$ penicillin $/ 100 \mu \mathrm{g} / \mathrm{ml}$ streptomycin $\left(\mathrm{Gibco}^{\circledR}\right.$, Thermo Fisher Scientific, Schwerte, Germany) in the presence of Treg expansion beads (Miltenyi Biotec, Bergisch Gladbach, Germany) at a beadto-cell ratio of 4:1. During expansion, fresh culture medium was added every 2-3 days.

\section{Dextran (Dex)-CAR Generation}

Dextran-specific CAR-Tregs with varying extracellular spacer domains were generated using lentiviral vectors encoding for a PGK promoter-driven AC146-derived single-chain variable fragment (scFv) (vh/vl orientation) linked to a human IgG4 hinge (L, M, XS) (53) or a human CD8 hinge (S) in combination with a CD8 transmembrane domain and the intracellular signaling modules of $\mathrm{CD} 137$ and $\mathrm{CD} 3 \zeta$. Additional lentiviral constructs shared the same scFv, an XS spacer, and the CD8 transmembrane region but differed with regard to their costimulatory and signaling domains consisting of either $\mathrm{CD} 3 \zeta$ or $\mathrm{CD} 3 \varepsilon$ without any costimulation or in combination with ICOS, CD28, CD134, CD137, or 
PD-1. All constructs contained a P2A-linked $\triangle$ LNGFR. Lentiviral supernatants were generated by co-transfection of HEK293T cells with the expression vector and packaging plasmids. One day prior to transfection, $3 \times 10^{6}$ HEK293T cells were seeded in a $10-\mathrm{cm}$ cell culture dish in complete DMEM (cDMEM) consisting of DMEM $\left(\right.$ Gibco $\left.^{\circledR}\right),+10 \%$ FCS $+100 \mathrm{U} / \mathrm{ml}$ penicillin, $100 \mu \mathrm{g} / \mathrm{ml}$ streptomycin $+50 \mu \mathrm{M}$ 2-Mercaptoethanol (all Thermo Fisher Scientific, Schwerte, Germany). Cells were transiently transfected with $0.84 \mu \mathrm{g}$ pMDG-2.VSV-G, $5.16 \mu \mathrm{g}$ pCMV $\Delta$ R8.74, and $3.35 \mu \mathrm{g}$ Dex-CAR plasmids diluted in $\mathrm{ddH}_{2} \mathrm{O}$ supplemented with $2.5 \mathrm{M}$ $\mathrm{CaCl}_{2}$. While aerating, $2 \mathrm{ml}$ of $2 \times \mathrm{HBS}$ buffer $(136.89 \mathrm{mM} \mathrm{NaCl}$, $4.96 \mathrm{mM} \mathrm{KCl}, 1.76 \mathrm{mM} \mathrm{Na}_{2} \mathrm{HPO}_{4}, 20.98 \mathrm{mM}$ HEPES in $\mathrm{ddH}_{2} \mathrm{O}$, $\mathrm{pH}=6.75-6.76)$ were slowly added to the solution, and $2 \mathrm{ml}$ of the transfection solution was added dropwise to the cells. The medium containing the transfection solution was removed after $4 \mathrm{~h}$, and cells were washed twice with prewarmed PBS before fresh CDMEM was added. After $48 \mathrm{~h}$, lentiviral supernatants were harvested, filtered $(0.45 \mu \mathrm{m})$, and used directly or stored at $-80^{\circ} \mathrm{C}$ for up to 6 months.

\section{Treg Transduction and Activation}

CD25+ Tregs were isolated and cultured as described above, and on $\mathrm{d} 3$ culture medium was replaced with the respective lentiviral supernatants supplemented with $4 \mu \mathrm{g} / \mathrm{ml}$ protaminsulfate (SigmaAldrich, Schnelldorf, Germany). Cells were spinoculated on 96-well plates coated with retronectin (Takara Bio via Clontech Laboratories, Saint-Germain-en-Laye, France) for $90 \mathrm{~min}$ at $800 \times g$ and $32^{\circ} \mathrm{C}$. After centrifugation, viral supernatant was removed, and "Treg expansion medium" was added to the cells. Untransduced Tregs andCAR-Tregswere expanded for 10-12 days, and medium was replaced every 2-3 days. Tregs were rested for 2 days without magnetic bead particles in RPMI-1640 (Gibco ${ }^{\circledR}$, Thermo Fisher Scientific, Schwerte, Germany) + 5\% (v/v) human AB-serum (Sigma-Aldrich, Schnelldorf, Germany) $+100 \mathrm{U} / \mathrm{ml}$ penicillin $/ 100 \mu \mathrm{g} / \mathrm{ml}$ streptomycin $\left(\mathrm{Gibco}^{\circledR}\right.$, Thermo Fisher Scientific, Schwerte, Germany) before 6 h restimulation with Treg expansion beads (4:1 bead-to-cell ratio, Miltenyi Biotec, Bergisch Gladbach, Germany), soluble FITC Dex (MW: 2,000,000, $2 \mu \mathrm{g} / \mathrm{ml}$, Sigma-Aldrich, Schnelldorf, Germany), bead-bound Dex (1:100; Dex-coated microbeads in PBS, Miltenyi Biotec, Bergisch Gladbach, Germany), or $10 \mathrm{ng} / \mathrm{ml}$ PMA and $500 \mathrm{ng} / \mathrm{ml}$ ionomycin (Sigma-Aldrich, Schnelldorf, Germany). For cytokine staining, $5 \mu \mathrm{g} / \mathrm{ml}$ Brefeldin A (Sigma-Aldrich, Schnelldorf, Germany) were added for the last $4 \mathrm{~h}$ of stimulation. $1 \mu \mathrm{g} / \mathrm{ml}$ anti-CD40 antibodies (Miltenyi Biotec, Bergisch Gladbach, Germany) were added to the stimulation when CD154 was stained on the surface. When expression was analyzed together with cytokines, intracellular staining of CD137 and CD154 was performed.

\section{Flow Cytometry}

Cells were stained in different combinations with the following antibodies according to manufacturer's recommendations: CD4-PE-Vio770, CD4-APC-Vio-770, CD4-FITC, CD4-VioBlue (VIT4), CD25-VioBright FITC (4E3), CD127-FITC, CD127-PEVio770 (MB15-18C9), CD271 (LNGFR)-PE, CD271 (LNGFR)PE-Vio770 (ME20.4-1.H4), CD137-PE (4B4-1), CD154-APC, CD154-VioBlue (5C8), HLA-A2 (REA517), TNF- $\alpha$-PE-Vio770 (CA2), IL-2 APC-Vio770 (N7.48 A), IL-17-FITC (CZ8-23G1),
FoxP3-APC (3G3) (all Miltenyi Biotech, Bergisch Gladbach, Germany), CD25-BV421 (BC96), and IFN- $\boldsymbol{\gamma}$-PerCP Cy5.5 (4S.B3; both from Biolegend, San Diego, CA, USA). Viobility 405/520 Fixable Dye (Miltenyi Biotech, Bergisch Gladbach, Germany) or propidium iodide (Sigma-Aldrich, Schnelldorf, Germany) were used to exclude dead cells. Intracellular cytokine staining was performed using the Inside Stain Kit (Miltenyi Biotec, Bergisch Gladbach, Germany), and intracellular FoxP3 staining was performed using the FoxP3 Staining Buffer Set (Miltenyi Biotec, Bergisch Gladbach, Germany) all according to manufacturer's protocol. For staining of CAR surface expression, Tregs were incubated for $10 \mathrm{~min}$ with $2 \mu \mathrm{g} / \mathrm{ml}$ FITC-labeled Dex (MW: 2,000,000, Sigma-Aldrich, Schnelldorf, Germany) at $4^{\circ} \mathrm{C}$ together with labeling of other surface molecules. All data were acquired on a FACS Canto/LSRII (BD, Heidelberg, Germany) or MACS Quant Analyzer (Miltenyi Biotec, Bergisch Gladbach, Germany), and FACS sorting was performed on an Aria I, Aria II, or Influx Cell Sorter (BD, Heidelberg, Germany). FlowJo (TreeStar, Inc, Ashland, OR, USA) was used for data analysis.

\section{Quantification of Gene Expression}

The competitive expansion of Dex-CAR constructs with different signaling domains was analyzed by quantitative real-time PCR. DNA was isolated by Zymo Research Quick-DNA TM Miniprep Kit (Zymo Research, Freiburg, Germany) according to manufacturer's instructions, and gene expression was analyzed using $1 \times$ SYBR $^{\circledR}$ Green PCR Master Mix (Thermo Fisher Scientific, Schwerte, Germany) and $500 \mathrm{nmol}$ forward and reverse primers (TIB MOLBIOL, Berlin, Germany; Table S1 in Supplementary Material), respectively. Gene expression was analyzed on a StepOne ${ }^{\mathrm{TM}}$ Real-Time PCR System (Thermo Fisher Scientific, Schwerte) and normalized to expression of GAPDH.

\section{Methylation-Sensitive TSDR Real-time PCR}

Genomic DNA was isolated with the QIAamp DNA Mini Kit (Qiagen, Hilden, Germany) and between 50 and 1,200 ng were used for bisulfite treatment (EpiTect, Qiagen, Hilden, Germany). Real-time PCR was performed in a final reaction volume of $20 \mu \mathrm{l}$ with $10 \mu \mathrm{l}$ FastStart Universal Probe Master (ROX, Roche Diagnostics, Mannheim, Germany), 100 ng Lamda DNA (NEB, Frankfurt a.M., Germany), 5 pmol methylation or non-methylation specific probe, 30 pmol methylation or non-methylation specific primers, and at least $15 \mathrm{ng}$ bisulfite-treated DNA or plasmid standard. Samples were analyzed in triplicates on an ABI 7500 Cycler (Thermo Fisher Scientific, Schwerte). The percentage of FoxP3 TSDR was calculated by dividing the non-methylated copy number by the total genomic FoxP3 copy number.

\section{Deep Bisulfite Amplicon Sequencing}

CD137+CD154- and CD137+CD154+ Tregs (CD25+CD127$\mathrm{CD} 45 \mathrm{RO}+$ ) from male donors were sorted and pooled, and cell pellets were digested with lysis buffer $(10 \mathrm{mM}$ Tris, $5 \mathrm{mM}$ EDTA, pH 8.0) with $1 \mathrm{mg} / \mathrm{ml}$ Proteinase K (Sigma-Aldrich, Schnelldorf, Germany) at $55^{\circ} \mathrm{C}$ overnight. Cell lysates were used directly for bisulfite conversion of $100 \mathrm{ng}$ DNA, which was treated 
with EZ-DNA methylation Gold kit (Zymo Research, Freiburg, Germany) according to manufacturer's instructions. Amplification of bisulfite-treated DNA was done by PCR, which was performed with either $2.5 \mathrm{U}$ HOT FIREPol ${ }^{\circledR}$ DNA Polymerase (Solis BioDyne,

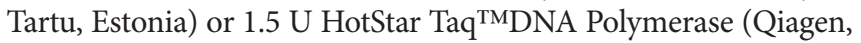
Hilden, Germany) with $20 \mathrm{ng}$ bisulfite-treated DNA, $0.2 \mathrm{mM}$ dNTPs, and $0.17 \mu \mathrm{M}$ bisulfite-specific primers (Table S2 in Supplementary Material) according to manufacturer's recommendations. Amplicons were purified with Agencourt Ampure XP beads (Beckman Coulter, Krefeld, Germany) according to manufacturer's instructions and sequenced on the Illumina MiSeq platform using MiSeq Reagent Kit v3 (Illumina, Inc., San Diego, USA). Sequencing results were processed with BiQ Analyzer HT (54) and filtered according to sequence identity $(>0.9)$, bisulfite conversion $(>0.95)$, and fraction of unrecognized sites $(<0.1)$. Data for methylation of the indicated regions in central and effector memory T cells were obtained from the study by Durek et al. (55).

\section{Suppression Assay}

Expanded Tregs were stimulated for $6 \mathrm{~h}$ with Treg expansion beads (4:1 bead:cell ratio, Miltenyi Biotec, Bergisch Gladbach, Germany) before CD137+CD154- and CD137+CD154+ Tregs were sorted and expanded. After 14 days of further expansion, Tregs were rested for 2 days in RPMI-1640 medium $\left(\mathrm{Gibco}^{\circledR}\right.$, Thermo Fisher Scientific, Schwerte, Germany) $+5 \%(\mathrm{v} / \mathrm{v})$ human AB-serum (Sigma-Aldrich, Schnelldorf, Germany) + $100 \mathrm{U} / \mathrm{ml}$ penicillin/ $100 \mu \mathrm{g} / \mathrm{ml}$ streptomycin $\left(\right.$ Gibco $^{\circledR}$, Thermo Fisher Scientific, Schwerte, Germany). Responder T cells (Tresps) with opposite HLA-A2 expression were isolated with the $\mathrm{CD} 4^{+} \mathrm{T}$ cell Isolation
Kit (Miltenyi Biotec, Bergisch Gladbach, Germany) according to manufacturer's instructions and stained with CellTrace ${ }^{\mathrm{TM}}$ Violet Cell Proliferation Kit (Thermo Fisher Scientific, Schwerte, Germany) at a final concentration of $2.5 \mu \mathrm{M}$. A total of $5 \times 10^{4}$ Tresps were co-cultured with Tregs in different ratios in 96-well flat bottom plates and stimulated with Treg Suppression Inspector (Miltenyi Biotec, Bergisch Gladbach, Germany). Dilution of proliferation dye was analyzed on day 7 . The percentage of inhibition was calculated as $\frac{(A-B)}{A} \times 100$, where $A$ is the uninhibited Tresp and $B$ is the inhibited Tresp.

\section{Statistical Analysis}

The exact values of $n$ and the respective statistical tests that were used to determine significances are specified in the respective figure legends. Statistical analysis was performed with GraphPad PRISM software 5.02 (GraphPad Inc., La Jolla, CA, USA). Significances are indicated with ${ }^{\star} p \leq 0.05,{ }^{* *} p \leq 0.01$, and ${ }^{* * *} p \leq 0.001$.

\section{RESULTS}

\section{In Vitro Expansion of CD25+ Tregs Compromises Purity}

The generation of sufficient numbers for Treg-based therapies or the modification of Treg functionality, e.g., by genetic engineering, requires prolonged in vitro expansion, which typically results in reduced frequencies of FoxP3+ Tregs (Figure 1A). FoxP3+

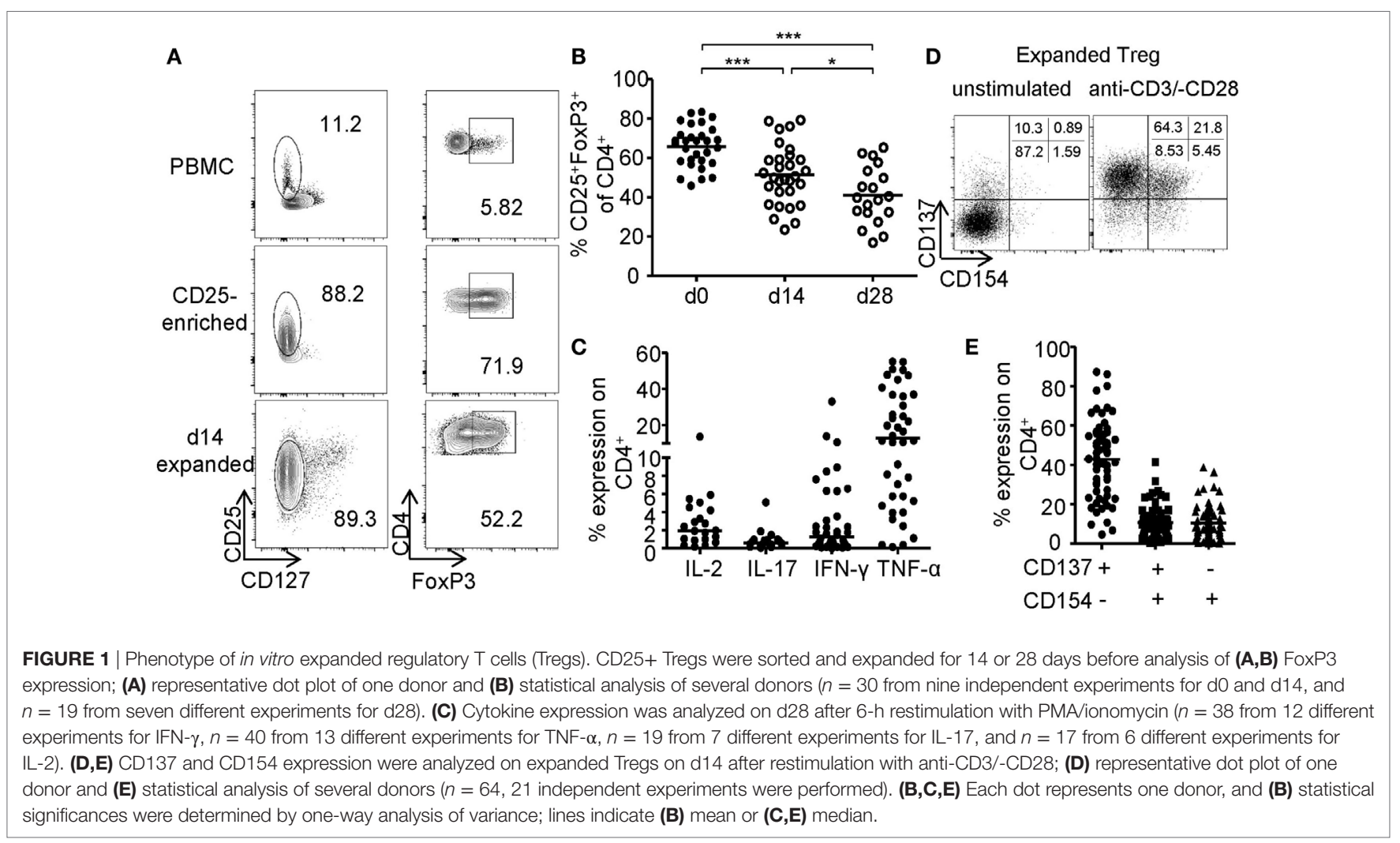


Tregs were enriched by GMP-compliant isolation using CD25 microbeads and expanded for 14-28 days using anti-CD3-/ anti-CD28-coated microspheres in the presence of IL-2 and rapamycin. Upon expansion, frequencies of FoxP3-expressing cells significantly decreased resulting in cultures with only $41.01 \%$ (mean $\pm 14.50 \%$ SD) FoxP3 + cells after 28 days compared to $65.79 \%$ (mean $\pm 10.46 \% \mathrm{SD}$ ) at the beginning of the culture (Figure 1B). Furthermore, high levels of pro-inflammatory cytokines (IFN- $\gamma$, IL-17, IL-2, and TNF- $\alpha$ ) were detected after restimulation of expanded cultures, indicating significant amounts of contaminating Teffs or potential Treg instabilities (Figure 1C). Independent of FoxP3, CD25 was expressed by almost all expanded cells, whereas CD127 expression was lost and could therefore no longer distinguish between Tregs and contaminating Teff (Figure 1A). Recently, converse expression of CD137 and CD154 has been described to discriminate between activated Tregs and Teffs ex vivo $(46-48,56)$. Therefore, we wanted to test whether these markers represent a universal activation signature, which allows discrimination between Tregs and Teffs after prolonged in vitro expansion. CD25+ sorted Tregs were expanded for 2 weeks as described (Figures 1A-C) and restimulated for $6 \mathrm{~h}$ with anti-CD3/anti-CD28. Flow cytometric analysis of CD137 and CD154 expression revealed the presence of three distinct subsets with differential CD137 and CD154 expression (Figure 1D). While most cells were defined by a CD137+CD154- phenotype, a variable percentage expressed the Teff-specific activation marker CD154 exhibiting either a CD137+CD154+ or CD137-CD154+ phenotype (Figure 1E).

\section{CD137+CD154- Expression Identifies Stable Tregs within Expansion Cultures}

To investigate the phenotype of CD137- and CD154-expressing cells within expanded Treg cultures, FoxP3 was stained on the different subsets after 6-h stimulation (Figures 2A,B). Remarkably, FoxP3+ Tregs were highly enriched within the CD137+CD154- Treg subset (mean \pm SD, 63.24\% \pm 14.92), while frequencies were significantly reduced or almost completely absent within CD137+CD154+ (mean \pm SD, $39.78 \pm 15.76 \%)$ and CD137-CD154+ cells (mean \pm SD, $24.32 \pm 13.71$ ). In addition, expression of effector cytokines was almost exclusively detected within CD154+ cells (Figures 2C,D). In contrast, CD137+CD154- Tregs completely lacked effector cytokine expression, in particular IL-2, IL-17, and IFN- $\gamma$, and they expressed only low levels of TNF- $\alpha$ (Figures 2C,D). Next, the in vitro suppressive capacities of CD137+CD154- and CD137+CD154+ Tregs were analyzed. While CD137+CD154- Tregs were highly efficient in inhibiting Teff proliferation, CD137+CD154+ Tregs exhibited an impaired suppressive potential compared to unsorted total Tregs (Figure 2E). To investigate the stability of FoxP3 expression within the different subsets, demethylation of the TSDR was analyzed revealing a striking difference between the different subsets. The TSDR was almost completely demethylated in CD137+CD154Tregs, hypermethylated in CD137+CD154+ cells and almost completely methylated in CD137-CD154+ cells (Figure 2F). This suggests either a gradual loss of TSDR demethylation correlating with the acquisition of CD154 expression or the co-existence of
Tregs and Teffs that were similarly able to express both markers. Furthermore, there was a strong association of the mean TSDR demethylation in unseparated Treg cultures with the frequency of CD137+CD154- T cells (Figure 2G), which was even stronger than correlation with the frequencies of FoxP3+ cells (Figure $2 \mathbf{H}$ ). The different subsets that were defined by CD137 and CD154 expression were also detected within the CD25+CD127- Treg compartment ex vivo (Figure 3A). As observed within expansion cultures, FoxP3+ cells were significantly enriched within CD137+CD154- Tregs and strongly reduced within CD154expressing subsets (Figure 3B). In addition to the TSDR, we also determined the methylation status of additional markers that have been shown to contribute to a stable epigenetic Treg signature and were differentially methylated between Tregs and Teffs $(57,58)$. CD137+CD154- Tregs exhibited an epigenetically stable Treg signature including demethylation of not only the TSDR but also ctla4, ikf2, $\operatorname{lrc} 32$, il2ra, and $\operatorname{tnfrsf9,}$, which were almost completely methylated in central and effector memory $\mathrm{T}$ cells (Figure 3C). Interestingly, CD137+CD154+ Tregs exhibited an intermediate Treg-Teff epigenetic signature that further suggests that CD137+CD154+ Tregs either represent a transitional state between both subsets or a mixture of Tregs and Teffs, which have acquired the potential to co-express both markers. Thus, our data suggest that CD137+CD154- expression represents a highly specific activation signature allowing to dissect Treg populations with different suppressive potential and epigenetic stability. This activation signature enables the rapid identification and sorting of epigenetically stable FoxP3+ Tregs ex vivo and within expanded cultures.

\section{CD137 Expression Enables Rapid Analysis of Treg Activation}

Regulatory $\mathrm{T}$ cell functionality is dependent on activation by the antigen receptor, and quality of the TCR signal has a major impact on their suppressive potential. However, so far it has been difficult to directly determine TCR activation of Tregs due to a lack of suitable markers. In particular, in mixed cultures of stable and instable Tregs or Teffs, the clear-cut assignment of certain functional readouts to stable Tregs has been impossible since commonly used parameters such as cytokine production are limited to Teffs and instable Tregs. Genetic engineering of Treg antigen specificity represents one important example for functional optimization of Tregs, e.g., for therapeutic purposes. However, it has so far not been possible to optimize artificial antigen receptor constructs for Tregs, which actually may differ from Teffs in their requirements for optimal activation, e.g., by different signal transduction moieties. Functional testing of bulk populations, e.g., for suppressive activity, or expansion are rather indirect, time consuming, and do not provide information on the level of individual cells. Therefore, we tested whether the Treg activation signature described here may allow fast functional in vitro testing of genetically engineered Tregs. To provide a controllable system for Treg activation, Treg specificity was redirected toward an innocuous exogenous antigen. To this end, a Dex-specific CAR construct was designed (Figure 4A) and CAR-Tregs were generated by lentiviral transduction. CAR-Tregs could be identified by 


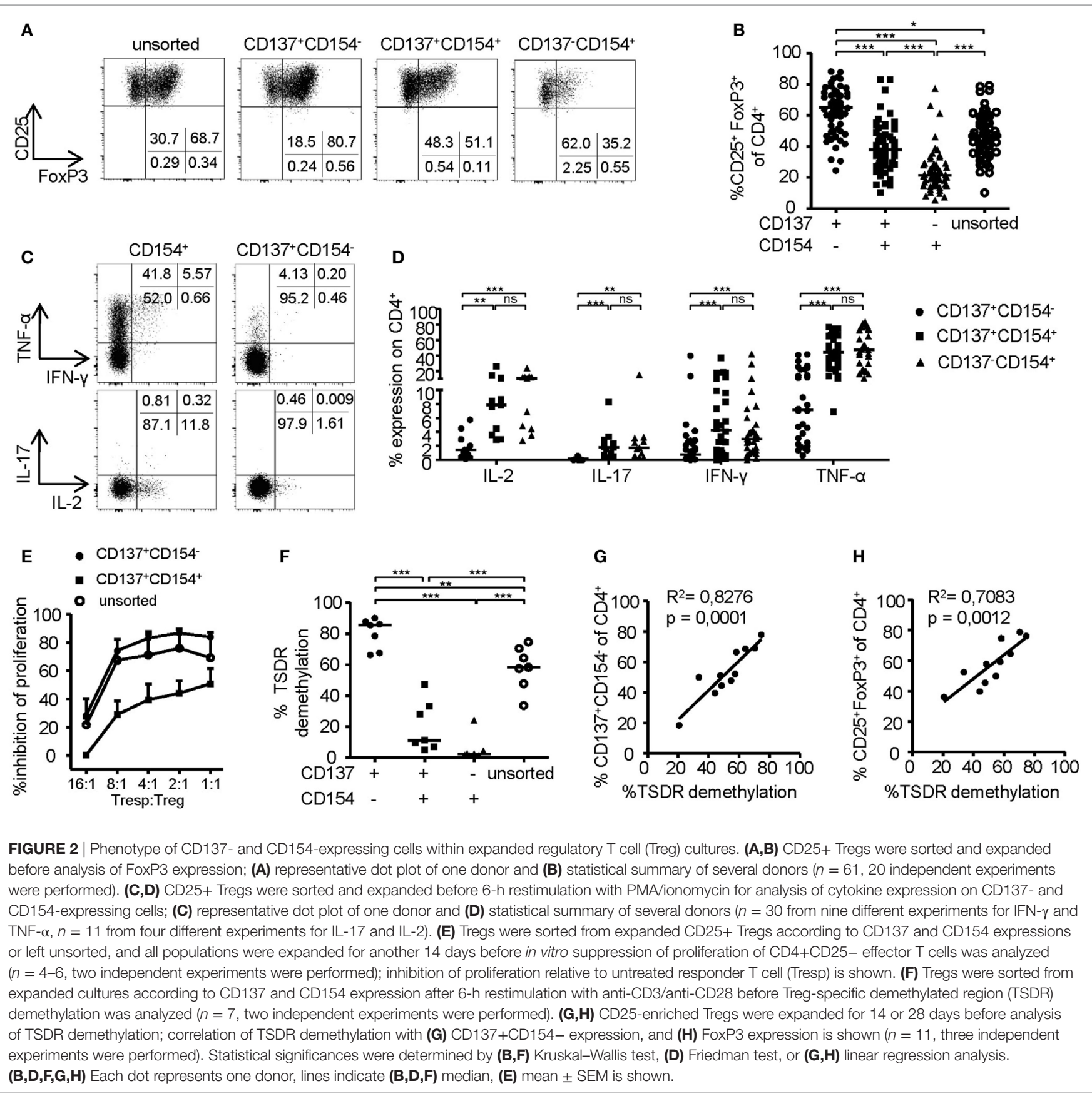

surface expression of LNGFR (Figures 4B,C) and Dex was bound by CAR-Tregs, indicating functional receptor expression and antigen binding (Figure 4D). Following antigen-specific stimulation with soluble or bead-bound Dex, CD137 was upregulated selectively on LNGFR + cells, but not on LNGFR - cells within the same culture (Figures 4E,F; Figures S1A,B in Supplementary Material). Next, the functionality of different extracellular spacer and intracellular signaling domains to activate Tregs in vitro was analyzed by CD137 expression. To this end, we generated different CAR constructs with long (L, 228aa), medium (M, 119aa), short (S, 45aa), and very short (XS, 12aa) extracellular spacer domains
(Figures S2A,B in Supplementary Material). In spite of superior Dex binding by $S$ spacers (Figure 5A), CD137 expression was only efficiently upregulated on CAR-Tregs with XS spacers even among cells that had bound Dex (Figure 5B). To investigate the impact of costimulation on CAR-Treg functionality, we generated several different Dex-specific CAR constructs with an optimized XS spacer consisting of $\mathrm{CD} 3 \zeta$ signaling combined with CD28, CD137, ICOS, CD134, or PD-1 costimulation. To control for the effect of costimulation alone, we generated CAR constructs with $\mathrm{CD} 28-\mathrm{CD} \varepsilon$ and $\mathrm{CD} 137-\mathrm{CD} \varepsilon$ signaling (Figure S2C in Supplementary Material). In spite of similar transduction rates as 
A

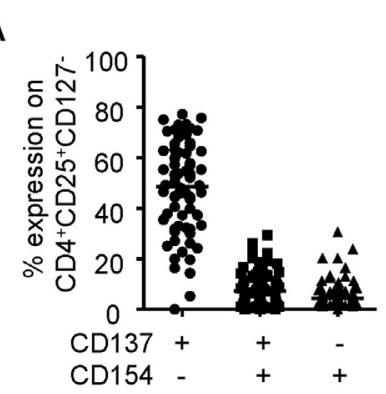

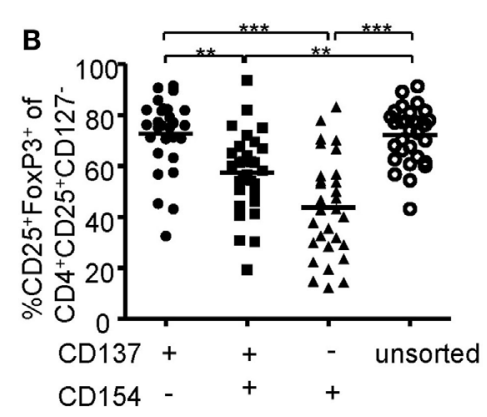

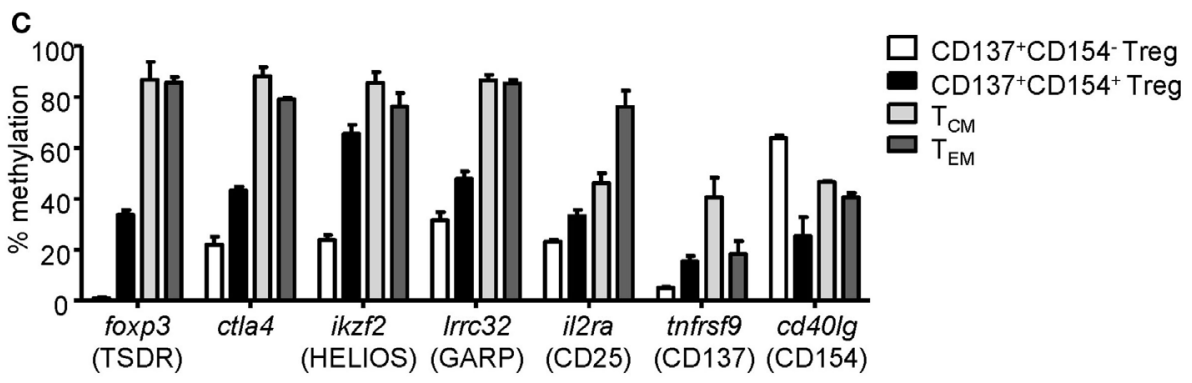

FIGURE 3 | CD137+CD154- expression identifies stable regulatory T cells (Tregs) ex vivo. (A) CD137 and CD154 expression were analyzed on CD25+CD127Tregs after 6-h stimulation with anti-CD3/anti-CD28 ex vivo ( $n=68,17$ independent experiments were performed). (B) Frequencies of FoxP3+ cells were analyzed among CD137- and CD154-expressing cells within the CD25+CD127- Treg compartment ( $n=30$, five independent experiments were performed). (C) CD137+CD154- and CD137+CD154+ Tregs (CD25+CD127-CD45RO+) were sorted after 6-h stimulation with anti-CD3/anti-CD28, and methylation of indicated regions was analyzed (data from two independent experiments are shown, and five and six male donors were pooled for each experiment). Methylation of central memory and effector memory T cells was derived from the study by Durek et al. (55). (A,B) Each dot represents one donor, lines indicate (A,B) median, (C) mean \pm SEM is shown; statistical significances were determined by (B) Kruskal-Wallis test.

determined by LNGFR expression (Figure S2D in Supplementary Material), CAR constructs differed in their ability to bind Dex (Figure S2E in Supplementary Material). Particularly CAR-Tregs with ICOS costimulation and $\mathrm{CD} \varepsilon$ signaling exhibited impaired binding of Dex, indicating inefficient CAR surface expression that potentially derives from structural inhibitions that result in unstable CAR expression (59-61). Although the remaining constructs were similarly able to bind Dex, only CAR-Tregs

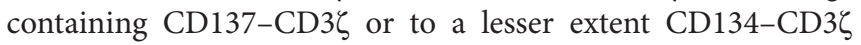
signaling were activated, but not CAR-Tregs that contained, e.g., commonly used CD28 costimulation (Figure 5C). Next, the impact of costimulation on the expansion of CAR-Tregs was analyzed. To directly compare the CAR constructs within a single culture, CAR-Tregs with different signaling domains were pooled and expansion of the different constructs was determined by quantitative real-time PCR. There was an enrichment of LNGFR+ cells in the presence of Dex compared to stimulation with anti-CD3/anti-CD28 (Figure 5D). To determine selective expansion of a particular construct, primers spanning constructspecific regions within the intracellular signaling domain were designed and expression was calculated relative to the beginning of the culture. Within this competitive co-culture, there was a selective expansion of CAR-Tregs with CD137-CD3ל signaling in the presence of Dex (Figure 5E), while polyclonal expansion did not favor any construct (Figure 5F). Interestingly, there was minor expansion with CD28 costimulation in some donors, while CD134 did not induce CAR-Treg proliferation. Taken together,
CD137 expression enabled the rapid evaluation of various spacer and signaling domains for CAR-mediated Treg activation in vitro revealing the superiority of CD137-CD3ל signaling over CD28 costimulation for CAR-Treg functionality.

\section{CD137+CD154- Expression Identifies Antigen-Activated FoxP3+ CAR-Tregs}

In vitro generated antigen-specific Tregs require increased safety measures to prevent contaminations with potentially autoaggressive Teffs. To this end, CAR-Tregs with an optimized extracellular XS spacer and intracellular CD137-CD3ל signaling domain were generated and sorted by LNGFR expression. While transgene expression (Figure 6A) and dextran binding (Figure 6B) were maintained upon expansion, FoxP3 expression was significantly reduced compared to ex vivo isolated Tregs (Figures 6C,D). Following 6-h antigen-specific stimulation, CD137 and CD154 were upregulated by dextran-reactive cells revealing variable frequencies of CD154-expressing cells, indicating the presence of significant numbers of CAR-expressing non-Tregs within this culture (Figures 6E,F). In line with our observations after polyclonal stimulation (Figures 2A-D and 3B), antigen-specific CD137+CAR- Tregs that lacked CD154 expression were characterized by high levels of FoxP3 expression (Figures 6E,G), low levels of TNF- $\alpha$, and complete absence of IL-2 expression (Figure 6H). In contrast, CD154 upregulation identified dextran-reactive cells that expressed low levels 


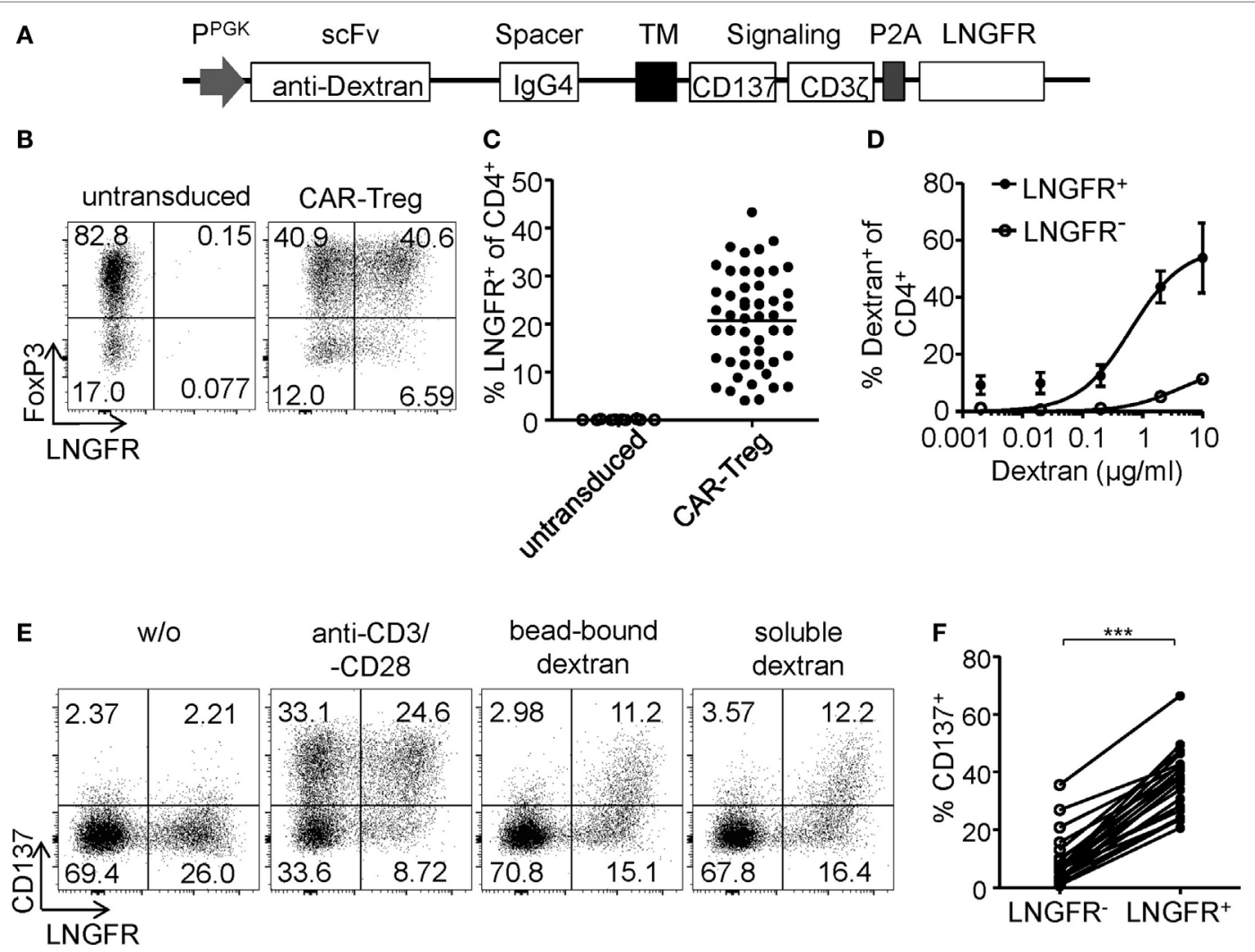

FIGURE 4 | CD137 expression identifies antigen-activated chimeric antigen receptor (CAR)-regulatory T cells (Tregs). (A) Schematic diagram of the dextranspecific CAR construct [transmembrane [TM], 2A peptide (P2A)]. (B-D) CAR-Tregs were generated by lentiviral transduction, and efficiencies were analyzed by (B-C) LNGFR expression; (B) representative dot plot of one donor and (C) statistical analysis of several donors is shown $(n=50$ from 16 independent experiments of CAR-Tregs and $n=12$ from 4 different experiments of untransduced Tregs are shown). (D) CAR surface expression was analyzed on LNGFR+ and LNGFRcells by incubation with FITC-labeled dextran ( $n=3-9$ from 1 to 3 independent experiments are shown). (E,F) Tregs were restimulated for 6 h with anti-CD3/ anti-CD28, bead-bound dextran or $2 \mu \mathrm{g} / \mathrm{ml}$ soluble FITC dextran, and expression of CD137 was analyzed. (E) Representative dot plots of one donor and (F) statistical analysis of bead-bound stimulation are shown $(n=21$, seven different experiments were performed). (C),F) Each dot represents one donor, and (C) lines indicate mean; (D) mean \pm SEM is shown. (F) Statistical significance was determined by paired $t$-test.

of FoxP3 and high levels of IL-2 and TNF- $\alpha$ (Figures 6G,H) and therefore represent antigen-specific non-Tregs with a significant inflammatory potential, which may cause adverse effects upon transfer in vivo. Taken together, we identified CD137+CD154- expression as Treg-specific activation signature, which enabled rapid analysis of in vitro generated Tregs in regard to their activation and stability emerging as a novel tool for the optimization of Treg efficacy and purity, e.g., for therapeutic applications.

\section{DISCUSSION}

The potential of in vitro generated Tregs to control chronic inflammatory diseases emerges as important target for clinical applications. To date, stability of expanded Tregs depends on the purity of the starting population as there are currently no unambiguous markers to separate stable Tregs from Teffs after expansion. In this study, we present a Treg-specific activation signature that enables the identification of epigenetically stable antigen-activated Tregs not only ex vivo but also following prolonged in vitro activation of human Tregs, which provides the opportunity to identify and purify Tregs after prior expansion.

In vitro generation of Tregs by large-scale expansion and/or genetic engineering remains a major challenge as there are currently no markers for the unambiguous identification of Tregs ex vivo or after prior in vitro culture. It has been proposed that naive Tregs represent a particularly stable Treg subset (62-66). Indeed, cord blood-derived CD25+ Tregs, consisting mainly of naive Tregs, were successfully expanded in vitro and have proven safety and efficacy in allogeneic umbilical cord blood transplantation (3-5). However, limited availability of cord blood and low frequencies of naive Tregs in adult blood currently prevent their large-scale clinical application. Alternatively, expanded FACS-sorted CD25+CD127- Tregs have been used in autologous settings for treatment of autoimmunity $(8,12)$. Yet, FACS sorting is still not routinely applicable under GMP conditions, and even expansion of FACS-sorted CD25+CD127- Tregs fails to eliminate non-Treg contaminations $(67,68)$. Clinical Treg isolation protocols are largely based on magnetic separation of CD25-expressing T cells $(1,4,7,69-71)$. Although this enriches 

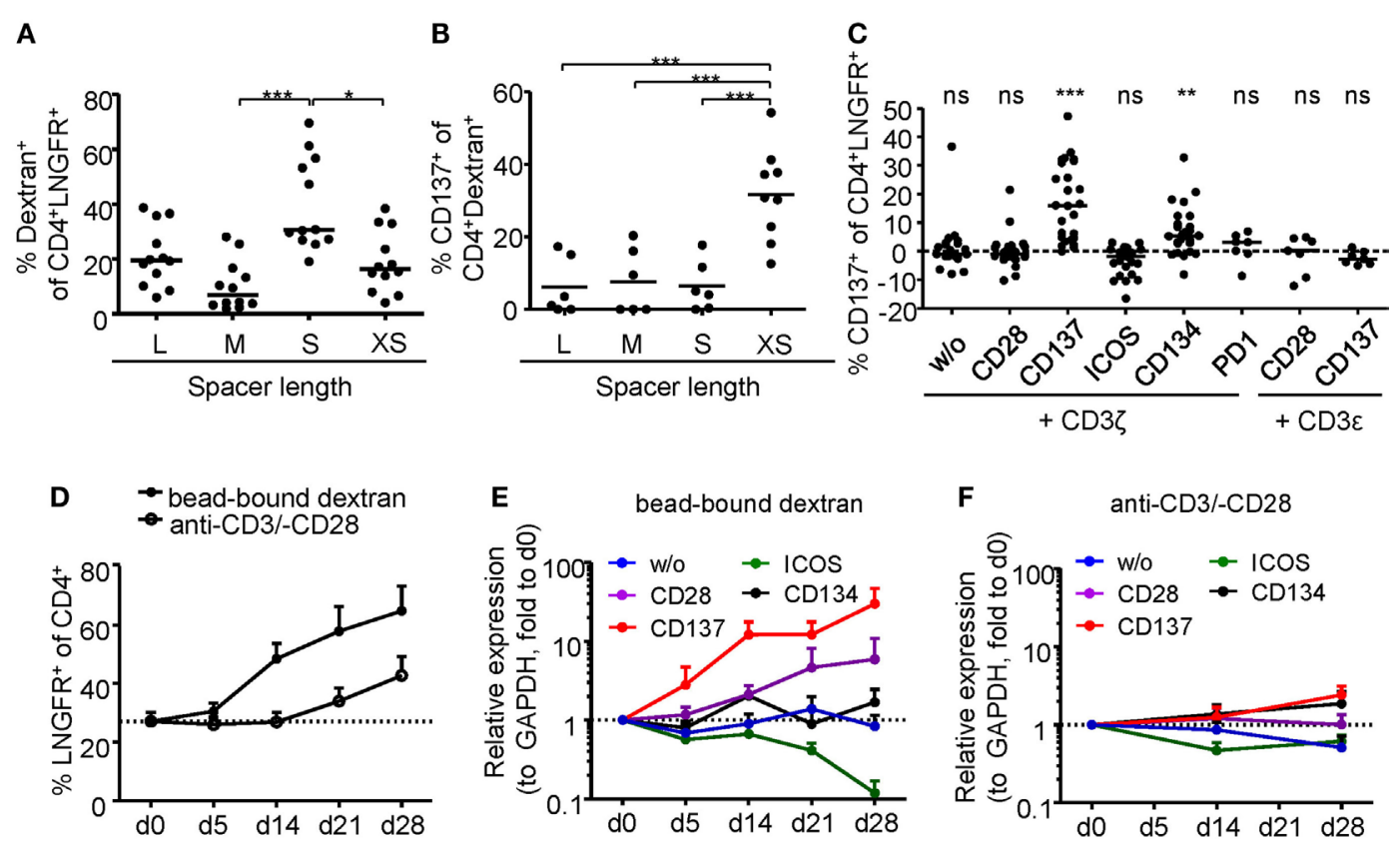

FIGURE 5 | Comparison of regulatory T cell (Treg) activation by different chimeric antigen receptor constructs. (A-B) CD25-enriched Tregs were transduced with dextran (Dex)-CAR constructs with different spacer lengths ( $\mathrm{L}=228 \mathrm{aa}, \mathrm{M}=119 \mathrm{aa}, \mathrm{S}=45 \mathrm{aa}$, XS = 12aa), and (A) binding of FITC-labeled Dex was analyzed ( $n=12$, four independent experiments were performed). (B) CAR-Tregs were restimulated for $6 \mathrm{~h}$ with $2 \mu \mathrm{g} / \mathrm{ml}$ FITC-labeled Dex, and CD137 expression was analyzed on Dex-binding cells; CD137 expression in unstimulated samples was subtracted, and negative values were set to 0 ( $n=6-9$, and two to three independent experiments were performed). (C-F) CD25-enriched Tregs were transduced with Dex-CAR constructs with different costimulatory domains

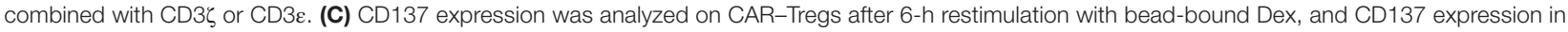
unstimulated samples was subtracted ( $n=22-26$, seven to eight different experiments were performed). (D-F) CAR-Tregs with different signaling domains were pooled and expanded in the presence of anti-CD3/anti-CD28 or bead-bound Dex; (A) LNGFR expression was analyzed at different time points $(n=5-7$, two to three different experiments were performed). (E,F) Expression (relative to GAPDH) of the different signaling domains with CD3C was determined at different time points of expansion with $(\mathbf{E})$ bead-bound Dex or $\mathbf{( F )}$ anti-CD3/anti-CD28. Expression was quantified by qPCR and normalized to relative expression on d0 $(n=7$, three different experiments were performed). Statistical significances were determined by (A) Kruskal-Wallis test, (B) one-way analysis of variance, or (C) Wilcoxon signed-rank test indicating activation above background. (A-C) Each dot represents one donor, lines indicate (A,C) median, or (B) mean; (D-F) mean \pm SEM is shown.

FoxP3+ Tregs ex vivo, purity is highly variable and depends on the composition of the starting material, i.e., cord blood, adult peripheral blood, or leukapheresis. Furthermore, non-Tregs can acquire a CD25+CD127- phenotype in vivo or upon in vitro culture and upregulate FoxP3 without acquisition of regulatory functions (72-75). Therefore, the lack of markers for the isolation of Tregs ex vivo as well as for their purification after prior expansion represents a significant technological challenge. Furthermore, the functional optimization of Tregs is hampered by the lack of Tregspecific activation markers, which allow discrimination between activated Tregs and activated Teffs to permit a direct evaluation of signals and pathways required for Tregs versus Teffs. Thus, the Treg-specific activation signature identified here provides a convenient tool to improve purity and function of human Tregs and to overcome a major hurdle for in vitro generation of functionally optimized Tregs for therapeutic applications.

In this study, CD137+CD154- expression was shown to selectively identify epigenetically stable antigen-activated Tregs within in vitro expanded cultures. It has been shown that FoxP3 expression is unable to distinguish between Tregs and non-Tregs after prolonged in vitro expansion, whereas TSDR demethylation enabled unambiguous identification of suppressive Treg clones (76). We show a striking linear correlation of CD137+CD154expression with TSDR demethylation revealing the potential of this surface marker combination to identify epigenetically stable FoxP3+ Tregs. Treg instability has been observed upon in vitro expansion resulting in the loss of FoxP3 expression and acquisition of effector functions $(62-65,77)$ and also notable numbers of IFN- $\gamma$-producing CD25+CD127- cells have been shown in patients suffering from MS (78), T1D (79), arthritis (80-82), psoriasis (83), or inflammatory bowel disease (84-86). Furthermore, studies from mice have shown that Treg plasticity contributes to anti-helminth immune responses (87), but also to heighten chronic inflammation $(81,88,89)$ and allergy (90). Collectively, the contribution of Treg plasticity to immune responses and tolerance in humans remain to be determined in future studies, yet its potential to exaggerate immune pathologies represents a significant safety risk for adoptive transfer. Here, we show that plasticity including upregulation of effector functions and downregulation of FoxP3 as well as impaired suppressive capacities were restricted to CD154+ cells. With regard to their highly methylated TSDR, it can be assumed that CD137+CD154+ and CD137-CD154+ 

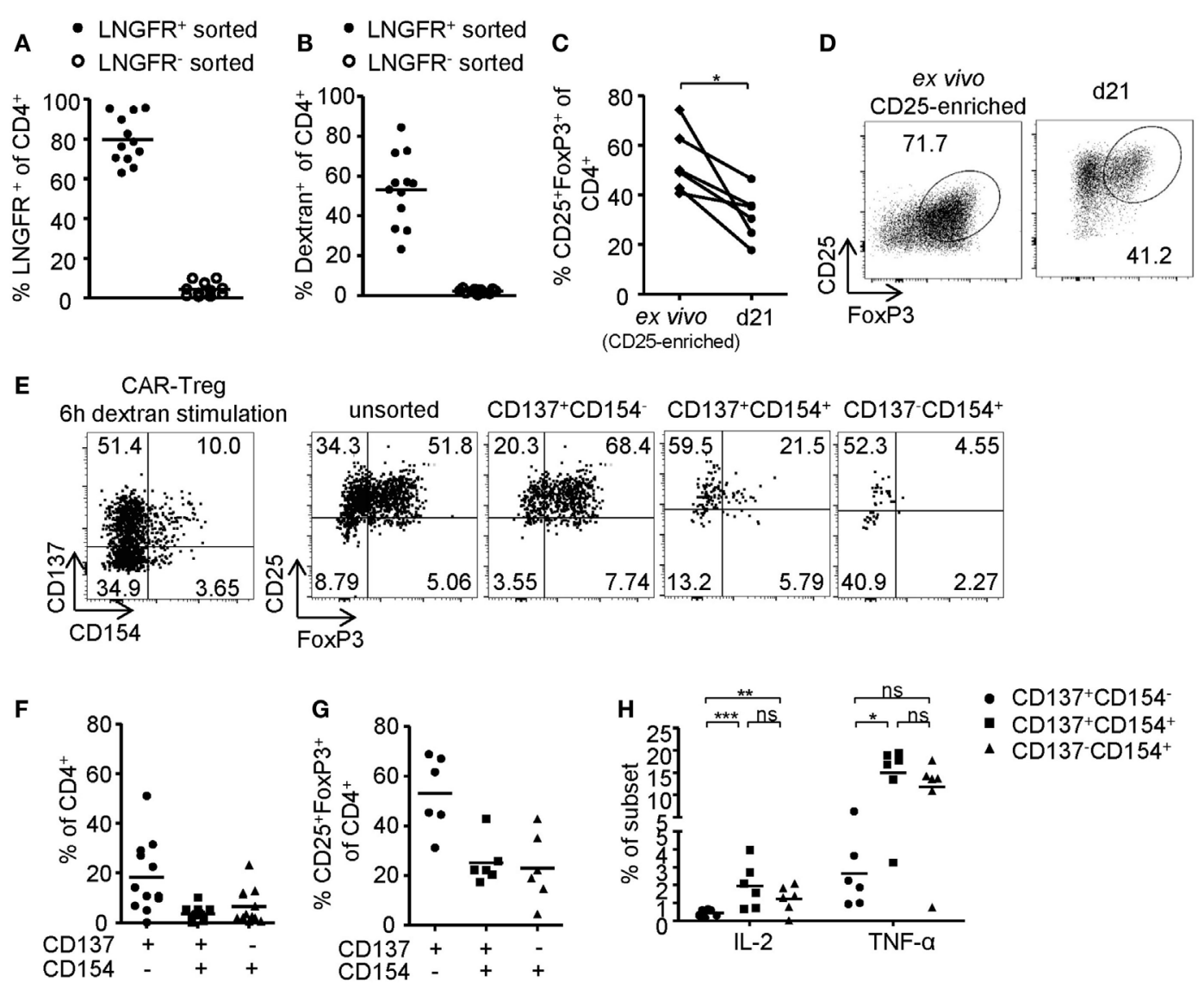

FIGURE 6 | Phenotype of antigen-activated chimeric antigen receptor (CAR)-regulatory T cells (Tregs). (A-H) LNGFR+ CAR-Tregs were sorted and expanded for 10-12 days before analysis of (A) LNGFR expression and (B) dextran-binding ( $n=12$ for LNGFR+ sorted and $n=11$ for LNGFR- sorted from four independent experiments). (C,D) FoxP3 expression in LNGFR+ sorted CAR-Tregs was analyzed ex vivo and after 21 days; (D) representative dot plot of one donor and (C) statistical summary of several donors ( $n=6$ from two independent experiments). (E-H) CAR-Tregs were restimulated for $6 \mathrm{~h}$ with bead-bound dextran and (E,G) FoxP3 expression ( $n=6$ from two independent experiments) and (E,F) CD137 and CD154 expression ( $n=12$ for from four independent experiments) were analyzed; $\mathbf{( E )}$ representative dot plot of one donor and $\mathbf{( F , G ) ~ s t a t i s t i c a l ~ s u m m a r y ~ o f ~ s e v e r a l ~ d o n o r s . ~ ( H ) ~ C y t o k i n e ~ e x p r e s s i o n ~ w a s ~ a n a l y z e d ~ o n ~ C D 1 3 7 - ~ a n d ~}$ CD154-expressing CAR-Tregs ( $n=6$ from two independent experiments). (A-C,F-H) Each dot represents one donor, and statistical significances were determined by $\mathbf{( C )}$ paired $t$-test or $\mathbf{( H )}$ Wilcoxon signed-rank test; lines indicate $\mathbf{( A , B )}$ median or $\mathbf{( F - H ) ~ m e a n . ~}$

cells contain significant frequencies of contaminating effector cells. Since CD137+CD154+ Tregs contained higher levels of FoxP3+ Tregs compared to cells that lacked CD137 expression, it can be hypothesized that instable Tregs were enriched within this subset, while CD137+CD154- Tregs were of remarkable phenotypic stability, which was mediated by a robust epigenetic Treg signature.

Here, we show a notable correlation of CD137 expression with a Treg phenotype, including FoxP3 expression and epigenetic Treg identity. Stable FoxP3 expression is dependent on TSDR demethylation (42-45), and it has been shown that cooperative complexes of FoxP3 and NFAT can directly regulate gene expression by suppressing effector molecules (e.g., IL-2) while upregulating Treg-associated genes (e.g., CTLA4) (91). Furthermore, Marson et al. showed that tnfrsf9 (CD137) is a direct target of FoxP3 (92) providing a possible link between CD137 expression with a stable Treg signature that was shown here. Yet, CD137 expression is not limited to the Treg lineage, but can also be upregulated by
CD4+ Teffs upon prolonged stimulation $(48,93)$. To account for the different kinetics of CD137 expression on Tregs and Teffs, it can be speculated that accessibility of the region is regulated by epigenetic modifications as CD137 has been shown to be hypomethylated in Tregs compared to Teffs (58). Similarly, tnfrsf9 was almost completely demethylated in CD137+CD154- Tregs while cd40lg (CD154) was highly methylated providing a molecular basis for rapid CD137 upregulation and lack of CD154 expression on stable Tregs. The importance of CD137 as costimulator for $\mathrm{T}$ cell activation has been well established (94), yet its role in Tregs remains elusive. CD137L is expressed on a variety of APCs and activated $\mathrm{T}$ cells and studies have shown that CD137-CD137L interaction increases Treg function (95-99) although impaired suppressive capacity has also been reported (100). Therefore, the function of CD137 expression on human Tregs remains to be determined, yet its rapid upregulation on Tregs could provide a versatile and wide-ranging mechanism enabling regulatory interactions with various immune cells (101). 
Redirecting Treg specificity by CARs is currently emerging as a promising approach for increased efficacy of therapeutic Tregs (33-41). However, the generation of functional CAR-Tregs in vivo requires evaluation of their functionality in vitro, which is currently limited due to the lack of Treg-specific activation markers. LAP and GARP have been shown to be upregulated on Tregs after polyclonal $(49,51,102,103)$ or alloantigenspecific (50) stimulation, yet expression requires prolonged stimulation and does not necessarily correlate with FoxP3 expression (104-106). Here, CD137 was shown to be upregulated selectively on FoxP3+ Tregs after 6-h stimulation, which enabled the rapid identification, isolation, and characterization of antigen-activated Tregs. To generate a controllable system for Treg activation, we redirected Treg specificity toward dextran as a model antigen. Dextran naturally exists in different sizes depending on the molecular weight and can be applied in different forms (e.g., soluble vs. bead-bound) providing a system for the rapid analysis of the effect of antigen binding on Treg activation. To date, little is known about the requirements of Treg activation via CAR stimulation, and individual CARs may differ in their specific requirements to optimally activate $\mathrm{T}$ cells (107). It has been proposed that the extracellular spacer $(53,108-112)$ and the intracellular signaling domain (113-119) have a significant impact on the functionality of CAR-T cells. Activation-induced CD137 expression enabled the rapid comparison of different CAR constructs in their ability to activate Tregs revealing superiority of CD137 costimulation compared to commonly used $\mathrm{CD} 28-\mathrm{CD} 3 \zeta$ signaling. It has been shown that CD28, but not CD137 costimulation, can initiate tonic signaling in conventional $\mathrm{T}$ cells leading to an exhaustion phenotype and limited efficacy (107). However, in that particular study, the degree of exhaustion varied between CARs with different scFv domains in spite of identical signaling domains. Therefore, it can be speculated that CD28 costimulation can be a potent inducer of $\mathrm{T}$ cell activation depending on the CAR. Nevertheless, it was shown here that $\mathrm{CD} 137-\mathrm{CD} 3 \zeta$ signaling was superior for in vitro CAR-Treg activation and expansion indicating potentially different signaling requirements than Tcon.

In conclusion, we show CD137+CD154- expression to be a highly specific Treg activation signature that enabled the identification and isolation of stable Tregs even after prolonged in vitro culture. We also show that this short-term activation signature allowed rapid screening and optimization of CAR functionality in Tregs. Taken together, universal application of this Treg-specific

\section{REFERENCES}

1. Di Ianni M, Falzetti F, Carotti A, Terenzi A, Castellino F, Bonifacio E, et al. Tregs prevent GVHD and promote immune reconstitution in HLA-haploidentical transplantation. Blood (2011) 117:3921-8. doi:10.1182/blood-2010-10-311894

2. Martelli MF, Di Ianni M, Ruggeri L, Falzetti F, Carotti A, Terenzi A, et al. HLA-haploidentical transplantation with regulatory and conventional T-cell adoptive immunotherapy prevents acute leukemia relapse. Blood (2014) 124:638-44. doi:10.1182/blood-2014-03-564401

3. Brunstein CG, Blazar BR, Miller JS, Cao Q, Hippen KL, McKenna DH, et al. Adoptive transfer of umbilical cord blood-derived regulatory $\mathrm{T}$ cells and early viral reactivation. Biol Blood Marrow Transplant (2013) 19:1271-3. doi:10.1016/j.bbmt.2013.06.004 activation signature will greatly improve Treg selection and functional optimization, such as for clinical applications in Tregbased therapies.

\section{ETHICS STATEMENT}

Peripheral blood was obtained from healthy donors that gave informed consent in accordance with the recommendations of the local ethics committee of the Charité Berlin. All subjects gave written informed consent in accordance with the Declaration of Helsinki. The protocol was approved by the local ethics committee of the Charité Berlin.

\section{AUTHOR CONTRIBUTIONS}

AN designed and performed experiments, interpreted the data, and wrote the manuscript. DL and AK generated CAR constructs and primers. $\mathrm{PB}$ designed experiments and interpreted the data. TH performed experiments. KV and BS performed TSDR analysis. JG, PG, JP, and JW designed, performed, and interpreted data from deep bisulfite amplicon sequencing. AS designed this study, interpreted the data, and wrote the manuscript. All authors provided discussion and reviewed the manuscript.

\section{ACKNOWLEDGMENTS}

We thank the DRFZ Flow Cytometry Core Facility, especially Toralf Kaiser and Jenny Kirsch, for cell sorting. This work was supported by the Leibniz ScienceCampus Chronic Inflammation (www.chronische-entzuendung.org).

\section{FUNDING}

This study was supported by grants from the Deutsche Forschungsgemeinschaft (DFG) SFB650 and the German Federal Ministry of Education and Science (BMBF) - Project InfectControl 2020 (Fkz 03ZZ0813A “ART4Fun”).

\section{SUPPLEMENTARY MATERIAL}

The Supplementary Material for this article can be found online at http://www.frontiersin.org/articles/10.3389/fimmu.2018.00199/ full\#supplementary-material.

4. Brunstein CG, Miller JS, Cao Q, McKenna DH, Hippen KL, Curtsinger J, et al. Infusion of ex vivo expanded T regulatory cells in adults transplanted with umbilical cord blood: safety profile and detection kinetics. Blood (2011) 117:1061-70. doi:10.1182/blood-2010-07-293795

5. Brunstein CG, Miller JS, McKenna DH, Hippen KL, DeFor TE, Sumstad D, et al. Umbilical cord blood-derived T regulatory cells to prevent GVHD: kinetics, toxicity profile, and clinical effect. Blood (2016) 127:1044-51. doi:10.1182/blood-2015-06-653667

6. Edinger $\mathrm{M}$, Hoffmann P. Regulatory $\mathrm{T}$ cells in stem cell transplantation: strategies and first clinical experiences. Curr Opin Immunol (2011) 23:679-84. doi:10.1016/j.coi.2011.06.006

7. Theil A, Tuve S, Oelschlägel U, Maiwald A, Döhler D, Oßmann D, et al. Adoptive transfer of allogeneic regulatory $\mathrm{T}$ cells into patients with chronic 
graft-versus-host disease. Cytotherapy (2015) 17:473-86. doi:10.1016/j. jcyt.2014.11.005

8. Trzonkowski P, Bieniaszewska M, Juścińska J, Dobyszuk A, Krzystyniak A, Marek N, et al. First-in-man clinical results of the treatment of patients with graft versus host disease with human ex vivo expanded CD4+CD25+CD127T regulatory cells. Clin Immunol (2009) 133:22-6. doi:10.1016/j.clim.2009. 06.001

9. Bluestone JA, Buckner JH, Fitch M, Gitelman SE, Gupta S, Hellerstein MK, et al. Type 1 diabetes immunotherapy using polyclonal regulatory T cells. Sci Transl Med (2015) 7:315ra189. doi:10.1126/scitranslmed.aad4134

10. Marek-Trzonkowska N, Myśliwec M, Siebert J, Trzonkowski P. Clinical application of regulatory T cells in type 1 diabetes. Pediatr Diabetes (2013) 14:322-32. doi:10.1111/pedi.12029

11. Marek-Trzonkowska N, Myśliwiec M, Dobyszuk A, Grabowska M, Derkowska I, Juścińska J, et al. Therapy of type 1 diabetes with CD4(+) CD25(high)CD127-regulatory T cells prolongs survival of pancreatic islets results of one year follow-up. Clin Immunol (2014) 153:23-30. doi:10.1016/j. clim.2014.03.016

12. Marek-Trzonkowska N, Mysliwiec M, Dobyszuk A, Grabowska M, Techmanska I, Juscinska J, et al. Administration of CD4+CD25highCD127regulatory $\mathrm{T}$ cells preserves beta-cell function in type 1 diabetes in children. Diabetes Care (2012) 35:1817-20. doi:10.2337/dc12-0038

13. Marek-Trzonkowska N, Myśliwiec M, Iwaszkiewicz-Grześ D, Gliwiński M, Derkowska I, Żalińska M, et al. Factors affecting long-term efficacy of T regulatory cell-based therapy in type 1 diabetes. J Transl Med (2016) 14:332. doi:10.1186/s12967-016-1090-7

14. Masteller EL, Warner MR, Tang Q, Tarbell KV, McDevitt H, Bluestone JA. Expansion of functional endogenous antigen-specific CD4+CD25+ regulatory T cells from nonobese diabetic mice. JImmunol (2005) 175:3053-9. doi:10.4049/jimmunol.175.5.3053

15. Tang Q, Henriksen KJ, Bi M, Finger EB, Szot G, Ye J, et al. In vitro-expanded antigen-specific regulatory $\mathrm{T}$ cells suppress autoimmune diabetes. J Exp Med (2004) 199:1455-65. doi:10.1084/jem.20040139

16. Tarbell KV, Petit L, Zuo X, Toy P, Luo X, Mqadmi A, et al. Dendritic cellexpanded, islet-specific $\mathrm{CD} 4+\mathrm{CD} 25+\mathrm{CD} 62 \mathrm{~L}+$ regulatory $\mathrm{T}$ cells restore normoglycemia in diabetic NOD mice. JExp Med (2007) 204:191-201. doi:10.1084/jem.20061631

17. Tarbell KV, Yamazaki S, Olson K, Toy P, Steinman RM. CD25+CD4+ T cells, expanded with dendritic cells presenting a single autoantigenic peptide, suppress autoimmune diabetes. J Exp Med (2004) 199:1467-77. doi:10.1084/ jem.20040180

18. Golshayan D, Jiang S, Tsang J, Garin MI, Mottet C, Lechler RI. In vitroexpanded donor alloantigen-specific $\mathrm{CD} 4+\mathrm{CD} 25+$ regulatory $\mathrm{T}$ cells promote experimental transplantation tolerance. Blood (2007) 109:827-35. doi:10.1182/blood-2006-05-025460

19. Joffre O, Santolaria T, Calise D, Al Saati T, Hudrisier D, Romagnoli P, et al. Prevention of acute and chronic allograft rejection with CD4+CD25+Foxp3+ regulatory T lymphocytes. Nat Med (2008) 14:88-92. doi:10.1038/nm1688

20. Nishimura E, Sakihama T, Setoguchi R, Tanaka K, Sakaguchi S. Induction of antigen-specific immunologic tolerance by in vivo and in vitro antigenspecific expansion of naturally arising Foxp3+CD25+CD4+ regulatory T cells. Int Immunol (2004) 16:1189-201. doi:10.1093/intimm/dxh122

21. Sagoo P, Ali N, Garg G, Nestle FO, Lechler RI, Lombardi G. Human regulatory $\mathrm{T}$ cells with alloantigen specificity are more potent inhibitors of alloimmune skin graft damage than polyclonal regulatory T cells. Sci Transl Med (2011) 3:83ra42. doi:10.1126/scitranslmed.3002076

22. Tsang JY, Ratnasothy K, Li D, Chen Y, Bucy RP, Lau KF, et al. The potency of allospecific Tregs cells appears to correlate with $\mathrm{T}$ cell receptor functional avidity. Am J Transplant (2011) 11:1610-20. doi:10.1111/j.1600-6143. 2011.03650.x

23. Tsang JY, Tanriver Y, Jiang S, Xue SA, Ratnasothy K, Chen D, et al. Conferring indirect allospecificity on $\mathrm{CD} 4+\mathrm{CD} 25+$ Tregs by TCR gene transfer favors transplantation tolerance in mice. J Clin Invest (2008) 118:3619-28. doi:10.1172/JCI33185

24. Trenado A, Charlotte F, Fisson S, Yagello M, Klatzmann D, Salomon BL, et al. Recipient-type specific CD4+CD25+ regulatory T cells favor immune reconstitution and control graft-versus-host disease while maintaining graftversus-leukemia. J Clin Invest (2003) 112:1688-96. doi:10.1172/JCI17702
25. Putnam AL, Safinia N, Medvec A, Laszkowska M, Wray M, Mintz MA, et al. Clinical grade manufacturing of human alloantigen-reactive regulatory $\mathrm{T}$ cells for use in transplantation. Am J Transplant (2013) 13:3010-20. doi:10.1111/ ajt.12433

26. Stephens LA, Malpass KH, Anderton SM. Curing CNS autoimmune disease with myelin-reactive Foxp3+ Treg. Eur JImmunol (2009) 39:1108-17. doi:10.1002/eji.200839073

27. Kieback E, Hilgenberg E, Stervbo U, Lampropoulou V, Shen P, Bunse M, et al. Thymus-derived regulatory $\mathrm{T}$ cells are positively selected on natural selfantigen through cognate interactions of high functional avidity. Immunity (2016) 44:1114-26. doi:10.1016/j.immuni.2016.04.018

28. Wright GP, Notley CA, Xue SA, Bendle GM, Holler A, Schumacher TN, et al. Adoptive therapy with redirected primary regulatory $\mathrm{T}$ cells results in antigen-specific suppression of arthritis. Proc Natl Acad Sci U S A (2009) 106:19078-83. doi:10.1073/pnas.0907396106

29. Fujio K, Okamoto A, Araki Y, Shoda H, Tahara H, Tsuno NH, et al. Gene therapy of arthritis with TCR isolated from the inflamed paw. J Immunol (2006) 177:8140-7. doi:10.4049/jimmunol.177.11.8140

30. Brusko TM, Koya RC, Zhu S, Lee MR, Putnam AL, McClymont SA, et al. Human antigen-specific regulatory $\mathrm{T}$ cells generated by $\mathrm{T}$ cell receptor gene transfer. PLoS One (2010) 5:e11726. doi:10.1371/journal.pone.0011726

31. Plesa G, Zheng L, Medvec A, Wilson CB, Robles-Oteiza C, Liddy N, et al. TCR affinity and specificity requirements for human regulatory T-cell function. Blood (2012) 119:3420-30. doi:10.1182/blood-2011-09-377051

32. Hull CM, Nickolay LE, Estorninho M, Richardson MW, Riley JL, Peakman M, et al. Generation of human islet-specific regulatory T cells by TCR gene transfer. J Autoimmun (2017) 79:63-73. doi:10.1016/j.jaut.2017.01.001

33. Mekala DJ, Geiger TL. Immunotherapy of autoimmune encephalomyelitis with redirected CD4+CD25+ T lymphocytes. Blood (2005) 105:2090-2. doi:10.1182/blood-2004-09-3579

34. Blat D, Zigmond E, Alteber Z, Waks T, Eshhar Z. Suppression of murine colitis and its associated cancer by carcinoembryonic antigen-specific regulatory T cells. Mol Ther (2014) 22:1018-28. doi:10.1038/mt.2014.41

35. Elinav E, Adam N, Waks T, Eshhar Z. Amelioration of colitis by genetically engineered murine regulatory $\mathrm{T}$ cells redirected by antigen-specific chimeric receptor. Gastroenterology (2009) 136:1721-31. doi:10.1053/j.gastro.2009.01.049

36. Elinav E, Waks T, Eshhar Z. Redirection of regulatory $\mathrm{T}$ cells with predetermined specificity for the treatment of experimental colitis in mice. Gastroenterology (2008) 134:2014-24. doi:10.1053/j.gastro.2008.02.060

37. Boardman DA, Philippeos C, Fruhwirth GO, Ibrahim MA, Hannen RF, Cooper D, et al. Expression of a chimeric antigen receptor specific for donor HLA class I enhances the potency of human regulatory T cells in preventing human skin transplant rejection. Am J Transplant (2017) 17:931-43. doi:10.1111/ajt.14185

38. MacDonald KG, Hoeppli RE, Huang Q, Gillies J, Luciani DS, Orban PC, et al. Alloantigen-specific regulatory $\mathrm{T}$ cells generated with a chimeric antigen receptor. J Clin Invest (2016) 126:1413-24. doi:10.1172/JCI82771

39. Noyan F, Zimmermann K, Hardtke-Wolenski M, Knoefel A, Schulde E, Geffers R, et al. Prevention of allograft rejection by use of regulatory T cells with an MHC-specific chimeric antigen receptor. Am J Transplant (2017) 17:917-30. doi:10.1111/ajt.14175

40. Skuljec J, Chmielewski M, Happle C, Habener A, Busse M, Abken H, et al. Chimeric antigen receptor-redirected regulatory $\mathrm{T}$ cells suppress experimental allergic airway inflammation, a model of asthma. Front Immunol (2017) 8:1125. doi:10.3389/fimmu.2017.01125

41. Yoon J, Schmidt A, Zhang AH, Königs C, Kim YC, Scott DW. FVIII-specific human chimeric antigen receptor T-regulatory cells suppress $\mathrm{T}$ - and B-cell responses to FVIII. Blood (2017) 129:238-45. doi:10.1182/blood-2016-07-727834

42. Baron U, Floess S, Wieczorek G, Baumann K, Grützkau A, Dong J, et al. DNA demethylation in the human FOXP3 locus discriminates regulatory $\mathrm{T}$ cells from activated FOXP3(+) conventional T cells. Eur J Immunol (2007) 37:2378-89. doi:10.1002/eji.200737594

43. Floess S, Freyer J, Siewert C, Baron U, Olek S, Polansky J, et al. Epigenetic control of the foxp3 locus in regulatory T cells. PLoS Biol (2007) 5:e38. doi:10.1371/journal.pbio.0050038

44. Huehn J, Polansky JK, Hamann A. Epigenetic control of FOXP3 expression: the key to a stable regulatory T-cell lineage? Nat Rev Immunol (2009) 9:83-9. doi:10.1038/nri2474 
45. Polansky JK, Kretschmer K, Freyer J, Floess S, Garbe A, Baron U, et al. DNA methylation controls Foxp3 gene expression. Eur J Immunol (2008) 38: 1654-63. doi:10.1002/eji.200838105

46. Bacher P, Heinrich F, Stervbo U, Nienen M, Vahldieck M, Iwert C, et al. Regulatory $\mathrm{T}$ cell specificity directs tolerance versus allergy against aeroantigens in humans. Cell (2016) 167:1067.e-78.e. doi:10.1016/j.cell. 2016.09.050

47. Bacher P, Kniemeyer O, Schönbrunn A, Sawitzki B, Assenmacher M, Rietschel E, et al. Antigen-specific expansion of human regulatory $\mathrm{T}$ cells as a major tolerance mechanism against mucosal fungi. Mucosal Immunol (2014) 7:916-28. doi:10.1038/mi.2013.107

48. Schoenbrunn A, Frentsch M, Kohler S, Keye J, Dooms H, Moewes B, et al. A converse 4-1BB and CD40 ligand expression pattern delineates activated regulatory $\mathrm{T}$ cells (Treg) and conventional $\mathrm{T}$ cells enabling direct isolation of alloantigen-reactive natural Foxp3+ Treg. J Immunol (2012) 189:5985-94. doi:10.4049/jimmunol.1201090

49. Tran DQ, Andersson J, Wang R, Ramsey H, Unutmaz D, Shevach EM. GARP (LRRC32) is essential for the surface expression of latent TGF-beta on platelets and activated FOXP3+ regulatory T cells. Proc Natl Acad Sci U S A (2009) 106:13445-50. doi:10.1073/pnas.0901944106

50. Noyan F, Lee YS, Zimmermann K, Hardtke-Wolenski M, Taubert R, Warnecke G, et al. Isolation of human antigen-specific regulatory $\mathrm{T}$ cells with high suppressive function. Eur J Immunol (2014) 44:2592-602. doi:10.1002/eji.201344381

51. Tran DQ, Andersson J, Hardwick D, Bebris L, Illei GG, Shevach EM. Selective expression of latency-associated peptide (LAP) and IL-1 receptor type I/II (CD121a/CD121b) on activated human FOXP3+ regulatory T cells allows for their purification from expansion cultures. Blood (2009) 113:5125-33. doi:10.1182/blood-2009-01-199950

52. Seddiki N, Cook L, Hsu DC, Phetsouphanh C, Brown K, Xu Y, et al. Human antigen-specific CD4(+) CD25(+) CD134(+) CD39(+) T cells are enriched for regulatory $\mathrm{T}$ cells and comprise a substantial proportion of recall responses. Eur J Immunol (2014) 44:1644-61. doi:10.1002/eji.201344102

53. Hudecek M, Sommermeyer D, Kosasih PL, Silva-Benedict A, Liu L, Rader C, et al. The nonsignaling extracellular spacer domain of chimeric antigen receptors is decisive for in vivo antitumor activity. Cancer Immunol Res (2015) 3:125-35. doi:10.1158/2326-6066.CIR-14-0127

54. Lutsik P, Feuerbach L, Arand J, Lengauer T, Walter J, Bock C. BiQ Analyzer HT: locus-specific analysis of DNA methylation by high-throughput bisulfite sequencing. Nucleic Acids Res (2011) 39:W551-6. doi:10.1093/ nar/gkr312

55. Durek P, Nordström K, Gasparoni G, Salhab A, Kressler C, de Almeida M, et al. Epigenomic profiling of human CD4+ T cells supports a linear differentiation model and highlights molecular regulators of memory development. Immunity (2016) 45:1148-61. doi:10.1016/j.immuni.2016.10.022

56. Bacher P, Kniemeyer O, Teutschbein J, Thön M, Vödisch M, Wartenberg D, et al. Identification of immunogenic antigens from Aspergillus fumigatus by direct multiparameter characterization of specific conventional and regulatory CD4+ T cells. J Immunol (2014) 193:3332-43. doi:10.4049/jimmunol.1400776

57. Arvey A, van der Veeken J, Plitas G, Rich SS, Concannon P, Rudensky AY. Genetic and epigenetic variation in the lineage specification of regulatory T cells. Elife (2015) 4:e07571. doi:10.7554/eLife.07571

58. Schmidl C, Klug M, Boeld TJ, Andreesen R, Hoffmann P, Edinger M, et al. Lineage-specific DNA methylation in T cells correlates with histone methylation and enhancer activity. Genome Res (2009) 19:1165-74. doi:10.1101/ gr.091470.109

59. Heuser C, Hombach A, Lösch C, Manista K, Abken H. T-cell activation by recombinant immunoreceptors: impact of the intracellular signalling domain on the stability of receptor expression and antigen-specific activation of grafted T cells. Gene Ther (2003) 10:1408-19. doi:10.1038/sj.gt.3302023

60. Nolan KF, Yun CO, Akamatsu Y, Murphy JC, Leung SO, Beecham EJ, et al. Bypassing immunization: optimized design of "designer $\mathrm{T}$ cells" against carcinoembryonic antigen (CEA)-expressing tumors, and lack of suppression by soluble CEA. Clin Cancer Res (1999) 5:3928-41.

61. Zhao Y, Wang QJ, Yang S, Kochenderfer JN, Zheng Z, Zhong X, et al. A herceptin-based chimeric antigen receptor with modified signaling domains leads to enhanced survival of transduced T lymphocytes and antitumor activity. J Immunol (2009) 183:5563-74. doi:10.4049/jimmunol.0900447
62. d'Hennezel E, Yurchenko E, Sgouroudis E, Hay V, Piccirillo CA. Single-cell analysis of the human $\mathrm{T}$ regulatory population uncovers functional heterogeneity and instability within FOXP3+ cells. J Immunol (2011) 186:6788-97. doi:10.4049/jimmunol.1100269

63. Hoffmann P, Boeld TJ, Eder R, Huehn J, Floess S, Wieczorek G, et al. Loss of FOXP3 expression in natural human $\mathrm{CD} 4+\mathrm{CD} 25+$ regulatory $\mathrm{T}$ cells upon repetitive in vitro stimulation. Eur J Immunol (2009) 39:1088-97. doi:10.1002/ eji.200838904

64. Hoffmann P, Eder R, Boeld TJ, Doser K, Piseshka B, Andreesen R, et al. Only the CD45RA+ subpopulation of CD4+CD25high T cells gives rise to homogeneous regulatory T-cell lines upon in vitro expansion. Blood (2006) 108:4260-7. doi:10.1182/blood-2006-06-027409

65. Arroyo Hornero R, Betts GJ, Sawitzki B, Vogt K, Harden PN, Wood KJ. CD45RA distinguishes CD4+CD25+CD127-/low TSDR demethylated regulatory $\mathrm{T}$ cell subpopulations with differential stability and susceptibility to tacrolimus-mediated inhibition of suppression. Transplantation (2017) 101:302-9. doi:10.1097/TP.0000000000001278

66. Miyara M, Yoshioka Y, Kitoh A, Shima T, Wing K, Niwa A, et al. Functional delineation and differentiation dynamics of human $\mathrm{CD} 4+\mathrm{T}$ cells expressing the FoxP3 transcription factor. Immunity (2009) 30:899-911. doi:10.1016/j. immuni.2009.03.019

67. Putnam AL, Brusko TM, Lee MR, Liu W, Szot GL, Ghosh T, et al. Expansion of human regulatory T-cells from patients with type 1 diabetes. Diabetes (2009) 58:652-62. doi:10.2337/db08-1168

68. Seay HR, Putnam AL, Cserny J, Posgai AL, Rosenau EH, Wingard JR, et al. Expansion of human Tregs from cryopreserved umbilical cord blood for GMP-compliant autologous adoptive cell transfer therapy. Mol Ther Methods Clin Dev (2017) 4:178-91. doi:10.1016/j.omtm.2016.12.003

69. Ukena SN, Höpting M, Velaga S, Ivanyi P, Grosse J, Baron U, et al. Isolation strategies of regulatory $\mathrm{T}$ cells for clinical trials: phenotype, function, stability, and expansion capacity. Exp Hematol (2011) 39:1152-60. doi:10.1016/j. exphem.2011.08.010

70. Hippen KL, Riley JL, June CH, Blazar BR. Clinical perspectives for regulatory T cells in transplantation tolerance. Semin Immunol (2011) 23:462-8 doi:10.1016/j.smim.2011.07.008

71. Hoffmann P, Boeld TJ, Eder R, Albrecht J, Doser K, Piseshka B, et al. Isolation of CD4+CD25+ regulatory T cells for clinical trials. Biol Blood Marrow Transplant (2006) 12:267-74. doi:10.1016/j.bbmt.2006.01.005

72. Allan SE, Crome SQ, Crellin NK, Passerini L, Steiner TS, Bacchetta R, et al. Activation-induced FOXP3 in human T effector cells does not suppress proliferation or cytokine production. Int Immunol (2007) 19:345-54. doi:10.1093/ intimm/dxm014

73. Gavin MA, Torgerson TR, Houston E, DeRoos P, Ho WY, Stray-Pedersen A, et al. Single-cell analysis of normal and FOXP3-mutant human T cells: FOXP3 expression without regulatory T cell development. Proc Natl Acad Sci U S A (2006) 103:6659-64. doi:10.1073/pnas.0509484103

74. Pillai V, Ortega SB, Wang CK, Karandikar NJ. Transient regulatory T-cells: a state attained by all activated human T-cells. Clin Immunol (2007) 123:18-29. doi:10.1016/j.clim.2006.10.014

75. Wang J, Ioan-Facsinay A, van der Voort EI, Huizinga TW, Toes RE. Transient expression of FOXP3 in human activated nonregulatory CD4+ T cells. Eur J Immunol (2007) 37:129-38. doi:10.1002/eji.200636435

76. Stockis J, Fink W, François V, Connerotte T, de Smet C, Knoops L, et al. Comparison of stable human Treg and Th clones by transcriptional profiling. Eur J Immunol (2009) 39:869-82. doi:10.1002/eji.200838807

77. Koenen HJ, Smeets RL, Vink PM, van Rijssen E, Boots AM, Joosten I. Human CD25highFoxp3pos regulatory $\mathrm{T}$ cells differentiate into IL-17-producing cells. Blood (2008) 112:2340-52. doi:10.1182/blood-2008-01-133967

78. Dominguez-Villar M, Baecher-Allan CM, Hafler DA. Identification of $\mathrm{T}$ helper type 1-like, Foxp3+ regulatory $\mathrm{T}$ cells in human autoimmune disease. Nat Med (2011) 17:673-5. doi:10.1038/nm.2389

79. McClymont SA, Putnam AL, Lee MR, Esensten JH, Liu W, Hulme MA, et al. Plasticity of human regulatory $\mathrm{T}$ cells in healthy subjects and patients with type 1 diabetes. J Immunol (2011) 186:3918-26. doi:10.4049/jimmunol. 1003099

80. Afzali B, Mitchell PJ, Edozie FC, Povoleri GA, Dowson SE, Demandt L, et al. CD161 expression characterizes a subpopulation of human regulatory $\mathrm{T}$ cells 
that produces IL-17 in a STAT3-dependent manner. Eur J Immunol (2013) 43:2043-54. doi:10.1002/eji.201243296

81. Komatsu N, Okamoto K, Sawa S, Nakashima T, Oh-hora M, Kodama T, et al. Pathogenic conversion of Foxp3+ T cells into TH17 cells in autoimmune arthritis. Nat Med (2014) 20:62-8. doi:10.1038/nm.3432

82. Pesenacker AM, Bending D, Ursu S, Wu Q, Nistala K, Wedderburn LR. CD161 defines the subset of FoxP3 $+\mathrm{T}$ cells capable of producing proinflammatory cytokines. Blood (2013) 121:2647-58. doi:10.1182/blood-2012-08-443473

83. Bovenschen HJ, van de Kerkhof PC, van Erp PE, Woestenenk R, Joosten I, Koenen HJ. Foxp3+ regulatory T cells of psoriasis patients easily differentiate into IL-17A-producing cells and are found in lesional skin. J Invest Dermatol (2011) 131:1853-60. doi:10.1038/jid.2011.139

84. Hovhannisyan Z, Treatman J, Littman DR, Mayer L. Characterization of interleukin-17-producing regulatory $\mathrm{T}$ cells in inflamed intestinal mucosa from patients with inflammatory bowel diseases. Gastroenterology (2011) 140:957-65. doi:10.1053/j.gastro.2010.12.002

85. Kryczek I, Wu K, Zhao E, Wei S, Vatan L, Szeliga W, et al. IL-17+ regulatory $\mathrm{T}$ cells in the microenvironments of chronic inflammation and cancer. J Immunol (2011) 186:4388-95. doi:10.4049/jimmunol.1003251

86. Ueno A, Jijon H, Chan R, Ford K, Hirota C, Kaplan GG, et al. Increased prevalence of circulating novel IL-17 secreting Foxp3 expressing CD4+ $\mathrm{T}$ cells and defective suppressive function of circulating Foxp3+ regulatory cells support plasticity between Th17 and regulatory T cells in inflammatory bowel disease patients. Inflamm Bowel Dis (2013) 19:2522-34. doi:10.1097/ MIB.0b013e3182a85709

87. Pelly VS, Coomes SM, Kannan Y, Gialitakis M, Entwistle LJ, Perez-Lloret J, et al. Interleukin 4 promotes the development of ex-Foxp3 Th2 cells during immunity to intestinal helminths. J Exp Med (2017) 214(6):1809-26. doi:10.1084/jem.20161104

88. Bailey-Bucktrout SL, Martinez-Llordella M, Zhou X, Anthony B, Rosenthal W, Luche $\mathrm{H}$, et al. Self-antigen-driven activation induces instability of regulatory $\mathrm{T}$ cells during an inflammatory autoimmune response. Immunity (2013) 39:949-62. doi:10.1016/j.immuni.2013.10.016

89. Zhou X, Bailey-Bucktrout SL, Jeker LT, Penaranda C, Martínez-Llordella M, Ashby M, et al. Instability of the transcription factor Foxp3 leads to the generation of pathogenic memory T cells in vivo. Nat Immunol (2009) 10:1000-7. doi:10.1038/ni.1774

90. Noval Rivas M, Burton OT, Wise P, Charbonnier LM, Georgiev P, Oettgen HC, et al. Regulatory $\mathrm{T}$ cell reprogramming toward a Th2-cell-like lineage impairs oral tolerance and promotes food allergy. Immunity (2015) 42:512-23. doi:10.1016/j.immuni.2015.02.004

91. Wu Y, Borde M, Heissmeyer V, Feuerer M, Lapan AD, Stroud JC, et al. FOXP3 controls regulatory $\mathrm{T}$ cell function through cooperation with NFAT. Cell (2006) 126:375-87. doi:10.1016/j.cell.2006.05.042

92. Marson A, Kretschmer K, Frampton GM, Jacobsen ES, Polansky JK, MacIsaac KD, et al. Foxp3 occupancy and regulation of key target genes during T-cell stimulation. Nature (2007) 445:931-5. doi:10.1038/nature05478

93. Wehler TC, Karg M, Distler E, Konur A, Nonn M, Meyer RG, et al. Rapid identification and sorting of viable virus-reactive $\mathrm{CD} 4(+)$ and $\mathrm{CD} 8(+)$ $\mathrm{T}$ cells based on antigen-triggered CD137 expression. J Immunol Methods (2008) 339:23-37. doi:10.1016/j.jim.2008.07.017

94. DeBenedette MA, Chu NR, Pollok KE, Hurtado J, Wade WF, Kwon BS, et al. Role of 4-1BB ligand in costimulation of $\mathrm{T}$ lymphocyte growth and its upregulation on M12 B lymphomas by cAMP. J Exp Med (1995) 181:985-92. doi:10.1084/jem.181.3.985

95. Zheng G, Wang B, Chen A. The 4-1BB costimulation augments the proliferation of CD4+CD25+ regulatory T cells. J Immunol (2004) 173:2428-34. doi:10.4049/jimmunol.173.4.2428

96. Zhang P, Gao F, Wang Q, Wang X, Zhu F, Ma C, et al. Agonistic anti-4$1 \mathrm{BB}$ antibody promotes the expansion of natural regulatory $\mathrm{T}$ cells while maintaining Foxp3 expression. Scand JImmunol (2007) 66:435-40. doi:10.1111/j.1365-3083.2007.01994.x

97. Elpek KG, Yolcu ES, Franke DD, Lacelle C, Schabowsky RH, Shirwan H. Ex vivo expansion of CD4+CD25+FoxP3 $+\mathrm{T}$ regulatory cells based on synergy between IL-2 and 4-1BB signaling. J Immunol (2007) 179:7295-304. doi:10.4049/jimmunol.179.11.7295

98. Kim J, Kim W, Kim HJ, Park S, Kim HA, Jung D, et al. Host CD25+CD4+Foxp3+ regulatory $\mathrm{T}$ cells primed by anti-CD137 mAbs inhibit graft-versus-host disease. Biol Blood Marrow Transplant (2012) 18:44-54. doi:10.1016/j.bbmt.2011.09.004

99. Lee J, Lee EN, Kim EY, Park HJ, Chang CY, Jung DY, et al. Administration of agonistic anti-4-1BB monoclonal antibody leads to the amelioration of inflammatory bowel disease. Immunol Lett (2005) 101:210-6. doi:10.1016/j. imlet.2005.06.001

100. Choi BK, Bae JS, Choi EM, Kang WJ, Sakaguchi S, Vinay DS, et al. 4-1BB-dependent inhibition of immunosuppression by activated CD4+CD25+ T cells. JLeukoc Biol (2004) 75:785-91. doi:10.1189/ jlb.1003491

101. Kwon B. Is CD137 ligand (CD137L) signaling a fine tuner of immune responses? Immune Netw (2015) 15:121-4. doi:10.4110/in.2015.15.3.121

102. Stockis J, Colau D, Coulie PG, Lucas S. Membrane protein GARP is a receptor for latent TGF-beta on the surface of activated human Treg. Eur J Immunol (2009) 39:3315-22. doi:10.1002/eji.200939684

103. Wang R, Kozhaya L, Mercer F, Khaitan A, Fujii H, Unutmaz D. Expression of GARP selectively identifies activated human FOXP3+ regulatory T cells. Proc Natl Acad Sci U S A (2009) 106:13439-44. doi:10.1073/pnas.0901965106

104. Abd Al Samid M, Chaudhary B, Khaled YS, Ammori BJ, Elkord E. Combining FoxP3 and Helios with GARP/LAP markers can identify expanded Treg subsets in cancer patients. Oncotarget (2016) 7:14083-94. doi:10.18632/ oncotarget.7334

105. Gandhi R, Farez MF, Wang Y, Kozoriz D, Quintana FJ, Weiner HL. Cutting edge: human latency-associated peptide+ T cells: a novel regulatory $\mathrm{T}$ cell subset. J Immunol (2010) 184:4620-4. doi:10.4049/jimmunol.0903329

106. Elkord E, Abd Al Samid M, Chaudhary B. Helios, and not FoxP3, is the marker of activated Tregs expressing GARP/LAP. Oncotarget (2015) 6:20026-36. doi:10.18632/oncotarget.4771

107. Long AH, Haso WM, Shern JF, Wanhainen KM, Murgai M, Ingaramo M, et al. 4-1BB costimulation ameliorates $\mathrm{T}$ cell exhaustion induced by tonic signaling of chimeric antigen receptors. Nat Med (2015) 21:581-90. doi: $10.1038 / \mathrm{nm} .3838$

108. Guest RD, Hawkins RE, Kirillova N, Cheadle EJ, Arnold J, O’Neill A, et al. The role of extracellular spacer regions in the optimal design of chimeric immune receptors: evaluation of four different scFvs and antigens. JImmunother (2005) 28:203-11. doi:10.1097/01.cji.0000161397.96582.59

109. Hudecek M, Lupo-Stanghellini MT, Kosasih PL, Sommermeyer D, Jensen MC, Rader C, et al. Receptor affinity and extracellular domain modifications affect tumor recognition by ROR1-specific chimeric antigen receptor T cells. Clin Cancer Res (2013) 19:3153-64. doi:10.1158/1078-0432.CCR-13-0330

110. James SE, Greenberg PD, Jensen MC, Lin Y, Wang J, Till BG, et al. Antigen sensitivity of CD22-specific chimeric TCR is modulated by target epitope distance from the cell membrane. J Immunol (2008) 180:7028-38. doi:10.4049/ jimmunol.180.10.7028

111. Hombach A, Heuser C, Gerken M, Fischer B, Lewalter K, Diehl V, et al. T cell activation by recombinant FcepsilonRI gamma-chain immune receptors: an extracellular spacer domain impairs antigen-dependent $\mathrm{T}$ cell activation but not antigen recognition. Gene Ther (2000) 7:1067-75. doi:10.1038/ sj.gt.3301195

112. Wilkie S, Picco G, Foster J, Davies DM, Julien S, Cooper L, et al. Retargeting of human T cells to tumor-associated MUC1: the evolution of a chimeric antigen receptor. J Immunol (2008) 180:4901-9. doi:10.4049/jimmunol.180. 7.4901

113. Finney HM, Akbar AN, Lawson AD. Activation of resting human primary $\mathrm{T}$ cells with chimeric receptors: costimulation from $\mathrm{CD} 28$, inducible costimulator, CD134, and CD137 in series with signals from the TCR zeta chain. J Immunol (2004) 172:104-13. doi:10.4049/jimmunol.172.1.104

114. Kowolik CM, Topp MS, Gonzalez S, Pfeiffer T, Olivares S, Gonzalez N, et al. CD28 costimulation provided through a CD19-specific chimeric antigen receptor enhances in vivo persistence and antitumor efficacy of adoptively transferred T cells. Cancer Res (2006) 66:10995-1004. doi:10.1158/00085472.CAN-06-0160

115. Loskog A, Giandomenico V, Rossig C, Pule M, Dotti G, Brenner MK. Addition of the CD28 signaling domain to chimeric T-cell receptors enhances chimeric T-cell resistance to T regulatory cells. Leukemia (2006) 20:1819-28. doi:10.1038/sj.leu.2404366

116. Milone MC, Fish JD, Carpenito C, Carroll RG, Binder GK, Teachey D, et al. Chimeric receptors containing CD137 signal transduction domains mediate 
enhanced survival of T cells and increased antileukemic efficacy in vivo. Mol Ther (2009) 17:1453-64. doi:10.1038/mt.2009.83

117. Savoldo B, Ramos CA, Liu E, Mims MP, Keating MJ, Carrum G, et al. CD28 costimulation improves expansion and persistence of chimeric antigen receptor-modified T cells in lymphoma patients. J Clin Invest (2011) 121:1822-6. doi:10.1172/JCI46110

118. Wang J, Jensen M, Lin Y, Sui X, Chen E, Lindgren CG, et al. Optimizing adoptive polyclonal $\mathrm{T}$ cell immunotherapy of lymphomas, using a chimeric T cell receptor possessing CD28 and CD137 costimulatory domains. Hum Gene Ther (2007) 18:712-25. doi:10.1089/hum.2007.028

119. Maus MV, June $\mathrm{CH}$. Making better chimeric antigen receptors for adoptive T-cell therapy. Clin Cancer Res (2016) 22:1875-84. doi:10.1158/1078-0432. CCR-15-1433
Conflict of Interest Statement: AK and DL are employees of Miltenyi Biotec. AS is a consultant for Miltenyi Biotec. All other authors declare that the research was conducted in the absence of any commercial or financial relationships that could be construed as a potential conflict of interest.

Copyright (c) 2018 Nowak, Lock, Bacher, Hohnstein, Vogt, Gottfreund, Giehr Polansky, Sawitzki, Kaiser, Walter and Scheffold. This is an open-access article distributed under the terms of the Creative Commons Attribution License (CC $B Y)$. The use, distribution or reproduction in other forums is permitted, provided the original author(s) and the copyright owner are credited and that the original publication in this journal is cited, in accordance with accepted academic practice. No use, distribution or reproduction is permitted which does not comply with these terms. 